


\section{Agrologistic Roadmaps Ghana}

Phase 2: Development of a roadmap methodology applied to the tomato and mango supply chains in Ghana

Author(s): Joost Snels

Han Soethoudt

Melanie Kok

Jerome Diaz

Report 1835 


\section{Colophon}

This report contains the results of the second phase of the project "Developing an efficient logistics network for fresh horticultural produce in Ghana". In this second phase two roadmaps (one for the mango and one tomato supply chains) are developed and builds further on insights, knowledge and results obtained from the previous 'inception' and 'diagnostic' phases. This report forms a whole with the previous two reports (Agrologistics Roadmap Ghana. Inception report. Wageningen Food \& Biobased Research, report number 1745, May 2017 and Agrologistics Roadmaps Ghana. Phase 1: selecting product market combinations and possible interventions. Wageningen Food \& Biobased Research, report number 1815, April 2018) and must therefore be considered in this context.

Title Agrologistic Roadmaps Ghana

Phase 2: Development of a roadmap methodology applied to the tomato and mango supply chains in Ghana

Authors Joost Snels, Han Soethoudt, Melanie Kok and Jerome Diaz

Number 1835

Date of publication June 2018

Version Final

Confidentiality No

DOI $\quad$ https://doi.org/10.18174/471479

ISBN 978-94-6343-432-4

Approved by Nicole Koenderink

Review Intern

Name reviewer Eelke Westra

Sponsor World Bank Group

Client Baher El-Hifnawi

Wageningen Food \& Biobased Research

P.O. Box 17

NL-6700 AA Wageningen

Tel: $+31(0) 317480084$

E-mail: info.fbr@wur.nl

Internet: www.wur.nl/foodandbiobased-research

(C) Wageningen Food \& Biobased Research, institute within the legal entity Stichting Wageningen Research All rights reserved. No part of this publication may be reproduced, stored in a retrieval system of any nature, or transmitted, in any form or by any means, electronic, mechanical, photocopying, recording or otherwise, without the prior permission of the publisher. The publisher does not accept any liability for inaccuracies in this report. 


\section{Abbreviations}

$\begin{array}{ll}\text { BSD } & \text { Black Spot Disease } \\ \text { CBO } & \text { Community Based Organisation } \\ \text { CODP } & \text { Customer Order Decoupling Point } \\ \text { CSIR } & \text { Council for Scientific and Industrial Research } \\ \text { DAES } & \text { Directorate of Agricultural Extension Services } \\ \text { FFH } & \text { Fresh Fruit Hub } \\ \text { GASIP } & \text { Ghana Agricultural Sector Investment Programme } \\ \text { MDTF-SL } & \text { Multi-Donor Trust Funds Sustainable Logistics } \\ \text { MoFA } & \text { Ministry of Food \& Agriculture } \\ \text { MOTI } & \text { Ministry of Trade \& Industry } \\ \text { NGO } & \text { Non-Governmental Organization } \\ \text { PDM } & \text { Porter Diamond Model } \\ \text { PHL } & \text { Post-harvest Losses } \\ \text { PMC } & \text { Product Market Combinations } \\ \text { PPP } & \text { Public Private Partnership } \\ \text { SIPC } & \text { Small-scale Intermediate Processing Centres } \\ \text { SWOT } & \text { Strengths - Weaknesses - Opportunities - Threats analysis } \\ \text { WBG } & \text { World Bank Group } \\ \text { WFBR } & \text { Wageningen Food \& Biobased Research }\end{array}$




\section{List of figures}

Figure 1: Conceptual framework for supply chain analysis (Source: Van der Vorst) .......................14

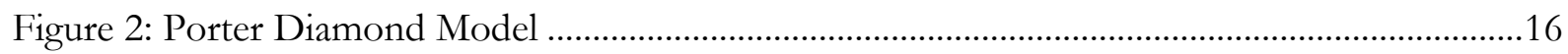

Figure 3: Conceptual description of the supply chain in its environment (Source: Wageningen

Food \& Biobased Research) .......................................................................................................19

Figure 4: Mill shop at Makola market, Accra, 2018 (Photo: Jan Verschoor) .....................................22

Figure 5: Mr Kwabena Adu-Gyamfi of Wenchi processing at their medium scale processing

facility. Wenchi processing uses the same facility to process tomatoes and mangoes, 2018 (Photo:

Jan Verschoor).

Figure 6: Conceptual description of the supply chain in its environment (Source: Wageningen

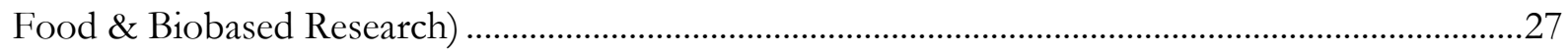

Figure 7: Consumer preferences for tomato products in Ghana [10] .............................................30

Figure 8: Proposal for value added products for the Ghanaian tomato processing industry

(Source: Wageningen Food \& Biobased Research) ...............................................................................

Figure 9: Mrs. Love Carr from Kokoby fruit processing, a medium scale mango processor near

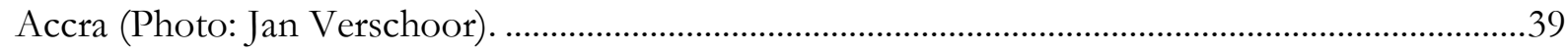

Figure 10: Conceptual framework on how post-harvest losses accrue and the dynamics of mitigation in Sub-Saharan Africa (adapted from [16])

Figure 11: Visual summary of anticipated systemic changes created by the Fresh Fruit Hub / Small-scale Intermediate Processing Centres (Source: Wageningen Food \& Biobased Research) 42 Figure 12: Medium \& small-scale mango processors roadmap (Source: Wageningen Food \& Biobased Research)

Figure 13: Schematic diagram for processing value added products from fresh tomatoes such as whole canned tomatoes and tomato paste. Side streams leading to tomato paste and silage are also shown.

Figure 14: Process diagram showing the difference between industrial and home processed tomato sauce/juice. Hot break process is used for industrial tomato paste production...... 


\section{List of tables}

Table 1: Elements related to the various parts of the supply chain structure ....................................15

Table 2: Elements to be addressed in Porter Diamond Model .......................................................18

Table 3: Varietals of tomato tested by MoFA and Heinz International ............................................24

Table 4: Physico-chemical properties of mature ripe and eating stages of the various mango

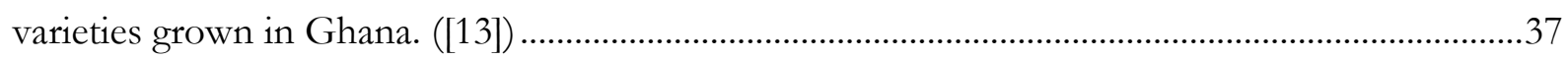

Table 5: Example year round plant production schedule (Source: Wageningen Food \& Biobased

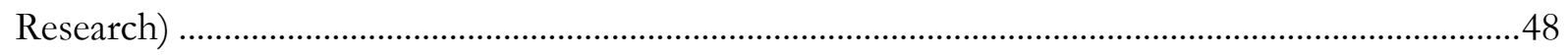

Table 6: List of all elements from the two models ................................................................................57

Table 7: Result of reallocation of elements of the models as input for the conceptual framework .58

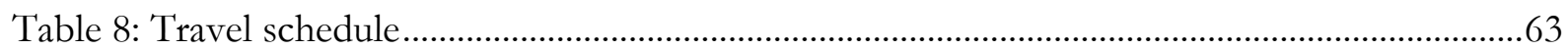




\section{Content}

Abbreviations 3

List of figures $\quad 4$

List of tables $\quad 5$

Acknowledgement 9

1 Introduction $\quad 10$

1.1.3 Overall vision, objective and scope of the project 11

2 Roadmap methodology 13

2.1 Food supply chain model 13

2.2 The Porter Diamond Model 16

$\begin{array}{ll}2.3 & \text { Setting up the roadmap } \\ \end{array}$

3 The tomato (processing) roadmap $\quad 20$

3.1 Step 1: Tomato processing sector ambition 20

3.2 Step 2: The market of tomato processing 20

3.2.1 Small/Micro level processors 21

3.2.2 Medium scale tomato processors in Ghana 22

3.2.3 Large scale tomato processors in Ghana 23

3.3 Step 3: Tomato processing sector challenges in relation to the ambition 23

$\begin{array}{lll}\text { 3.3.1 Tomato varieties } & 24\end{array}$

3.3.2 Stabilize tomato supply for local fresh and local processing markets 25

3.3.3 Improve raw material handling and process control for tomato processing at all levels. 26

3.3.4 Develop/propose a diverse portfolio of value added tomato products for the local Ghanaian market $\quad 26$

3.3.5 Standardization and training 26

3.4 Step 4: Relation to roadmap structure 26

$\begin{array}{lll}\text { 3.4.1 Tomato varietals } & 27\end{array}$

3.4.2 Stabilize tomato supply for local fresh and local processing markets 27

3.4.3 Improve raw material handling and process control for tomato processing at all levels 28

3.4.4 Develop/propose a diverse portfolio of value added tomato products for the local Ghanaian market 28

3.4.5 Standardization and training 28

3.5 Step 5: The current and target situation 29

$\begin{array}{lll}3.5 .1 & \text { Tomato Varieties } & 29\end{array}$

3.5.2 Stabilize tomato supply 29 
3.5.3 Improve raw material handling and process control for tomato processing at all levels 30

3.5.4 Develop/propose a diverse portfolio of value added tomato products for the local Ghanaian market $\quad 30$

3.5.5 Standardization and training 31

3.6 Step 6: Activities and resources 32

3.6.1 Tomato varieties $\quad 32$

3.6.2 Stabilize tomato supply 32

3.6.3 Improve raw material handling and process control for tomato processing at all levels $\quad 32$

3.6.4 Develop/propose a diverse portfolio of value added tomato products for the local Ghanaian market $\quad 33$

3.6.5 Standardization and training $\quad 34$

4 The mango roadmap $\quad 35$

4.1 Step 1: Mango supply chain ambition $\quad 35$

4.2 Step 2: The market for fresh and processed mango and mango industry 37

4.2.1 Mango varieties in Ghana $\quad 37$

4.2.2 Market for the Ghanaian mangoes $\quad 37$

4.2.3 Current state of mango processors in Ghana 38

4.2.4 Large scale mango processing in Ghana 38

4.2.5 Small/Micro level mango processing in Ghana 39

4.3 Step 3: Mango supply chain challenges in relation to the ambition 39

4.3.1 General challenge: Black Spot Disease / Sufficient supply of mango 39

4.3.2 General challenge: Improve pre- and post- harvest practices and operation to minimize losses 40

4.3.3 Challenge: Setting up a small-scale Fresh Fruit Hub / Small-scale Intermediate Processing Centre 41

4.4 Step 4: Relation to roadmap structure: the mango roadmap 42

4.5 Step 5: The current \& target situation 43

4.5.1 Determine the main functionalities of the Fresh Fruit Hub / Small-scale Intermediate Processing Centre 43

4.5.2 Functionality FFH/SIPC: Processing 46

4.5.3 Functionality FFH/SIPC: Training (office) = Improving harvest and first handling practices on-farm 49

4.5.4 Location of the FFH/SIPC 50

4.5.5 Ownership of the FFH/SIPC 51

4.5.6 Investment related to the FFH/SIPC 52

4.6 Step 6: Activities and resources 53

4.7 Concluding remarks mango roadmap $\quad 54$

5 Conclusion and remark $\quad 55$ 
Appendix A Elements from the 2 models used 57

Appendix B Important characteristics of processing tomato varieties 59

$\begin{array}{lll}\text { Appendix C Unit operations in tomato processing plants } & 60\end{array}$

Appendix D Validation mission (May 14-19, 2018) 63 


\section{Acknowledgement}

We would like to thank all stakeholders met during the field missions in Ghana: representatives from producer organizations, the private sector, exporters, funding agencies, and state officials. We are particularly grateful to Dan Acquaye, Juliana Asante-Dartey from Agri-Impact and their staff, who provided guidance and access to information, and co-organized the workshops and field missions. We are also very grateful to Nana Osei-Bonsu of the Private Enterprise Federation (PEF) for his insight, contacts and input during this project. We express our gratitude also to Mr. Papa Kow Bartels of Ministry of Trade and Industry (MoTI) in sharing his knowledge and network and participations in the workshops. In addition, we would like to thank Jan Verschoor (Wageningen Food \& Biobased Research) for his contribution during the validation mission of May 2018.

The peer reviewers are Dan Acquaye (Agribusiness and Market Development Expert of AgriImpact), Juliana Asante-Dartey (Finance and Organizational Management Expert of Agri-Impact) and Mr. Papa Kow Bartels (Director Logistics and Value Chain, Ministry of Trade and Industry) 


\section{Introduction}

\subsection{Background}

\subsubsection{The challenge of food losses globally and in Ghana}

Currently $30-40 \%$ of the total global food production is lost or wasted between field and consumer [1]. These losses are expected to increase as the changing diet patterns of the rising middle class in Africa will trigger a higher demand for off-the-shelf perishable foods such as dairy, fish, horticulture, etc. World population projections would require that overall food production should be raised by 60 to $70 \%$ in the decades preceding 2050 . To cope with this increasing food demand, governments have traditionally put emphasis on increased food production to the neglect of post-harvest management issues leading to significant food losses, which also means significant financial losses [2].

Ghana loses about $20-30 \%$ of cereals and legumes, and about $20-50 \%$ of roots, tubers, fruits and vegetables annually either in storage, during transport or at the market [3]. There is increased public and private sector awareness in Ghana to reduce post-harvest losses (PHL) through a prudent management approach. This conforms to the decision in 2014 by African governments to commit $10 \%$ of budgetary resources to agriculture and to working toward halving post-harvest losses from the current levels by 2025 (Malabo declaration). Because of the magnitude of PHL in Africa, the African Union Commission has -since 2012- strongly advised all African countries to develop national investment plans to reduce losses. The Government of Ghana has made the reduction of PHL her priority and set targets for the reduction of all post-harvest losses. The Government of Ghana is in the process of completing the development of a national investment plan (Ghana Agricultural Sector Investment Programme GASIP) to reduce losses and linking smallholder farmers to agribusinesses to enhance pro-poor growth (http://mofa.gov.gh/site/?page id=13706). Because of the focus on the reduction of PHL, many policies and programs regarding PHL are developed with the downside that these are not well enough aligned and coordinated and that an integral vision on agro-logistics, and on fresh fruit and vegetables in particular, is lacking.

\subsubsection{The Multi-Donor Trust Fund Sustainable Logistics}

In the area of agro-logistics, the MDTF-SL aims to assist developing countries in strengthening domestic food security and improving the competitiveness of agricultural exports through the improvement of logistics and reduction of food losses along the supply chains, especially between production zones, urban conglomerations and export hubs. There is little doubt that efficient logistics are a precondition for regions, countries, cities, and businesses to participate in the global economy, boost growth, and improve livelihoods ${ }^{1}$. Sustainable and efficient agrologistics is critical to the economic development of many developing countries. It boosts

1 bttp:/ / blogs.worldbank.org/transport/feed-future-let-s-make-logistics-and-transport-sustainable (seen 2018-06-25) 
agricultural productivity and improves food security for the growing urban population. It increases also employment and reduces poverty.

\subsubsection{Overall vision, objective and scope of the project}

Honouring the overarching aims of the MDTF-SL and considering the Ghanaian situation, the projects vision is to improve food security in Ghana through more efficient agro supply chains with a focus on reduction of post-harvest losses in these agro supply chains. The first objective to achieve this vision is to develop clear roadmaps with concrete interventions for two product market combinations (PMCs) -in agreement with the contractor; the scope of the project is to focus on post-harvest management for fruit and vegetables- leading to an efficient logistic network aiming at:

a. cost reduction;

b.improved food quality and reduction of food losses, and

c. improved market competitiveness for agriproducts.

The selected products based on the research done in phase 1 of this project are tomato and mango and the production regions are Brong-Ahafo and Ashanti.

\subsection{Building on preparatory studies}

Phase 1 of this project concluded for tomatoes that the most important interventions are cold storage opportunities and an improvement of the processing industry. For tomato was concluded that Ghana needs to boost the processing sector in the tomato production areas BrongAhafo/Ashanti region, not only on factory level (long term) but also on small and medium scale (short term). For mango, the conclusions are that currently the biggest issue is Black Spot Disease (BSD). However, related to post-harvest intervention it was concluded that a significant need exists for a hub that can offer various services such as handling, storing, packaging and processing. These results are taken as input for development of the roadmaps for both tomato and mango addressing the above-mentioned interventions.

\subsection{Objectives and outline of the report}

This report summarizes phase 2 of the project. Based on the results of the first phase ("Selecting product market combinations and possible interventions"), the objectives of this phase of the project are to develop a methodology for drawing a roadmap and to work out in more detail two roadmaps with interventions for the mango and tomato supply chains. Thus, a methodology is formulated for drawing up a roadmap in order to be used for similar initiatives in other countries

(Chapter 2). Based on this guideline and the third validation mission (May 14-18, 2018) both the roadmaps for tomato (Chapter 3) and mango (Chapter 4) are described. The report closes with an overview and concluding remarks (Chapter 5). 
This study is performed in the period of March 2017 until June 2018 by researchers of Wageningen Food \& Biobased Research (WFBR) in an objective and independent manner. It is commissioned by Baher El-Hifnawi and financed by the World Bank Group (WBG). 


\section{Roadmap methodology}

The main goal of the project is to obtain two roadmaps for opportunities in the post-harvest supply chain of fruits and vegetables in Ghana. These opportunities are identified in earlier stages of the project and discussed with stakeholders in a workshop (Kumasi, February 2018). Further details on how to move forward were discussed during a field mission in May 2018 in BrongAhafo, Ashanti and Accra. This input needs to be structured in roadmaps, one for tomato and one for mango. To this need a methodology is developed, that is described in this chapter

Remark: note that, in order to apply the roadmap methodology below, prerequisite research needs to be carried out with respect to product market combinations and regional preference. The decision on what product(s) and what region(s) are selected has been made in earlier stages, like in this project. These results are taken as a starting point for the roadmap.

A roadmap is a plan or strategy intended to achieve a particular goal. It consists of a set of interlinked and ordered activities, stakeholders and resources that is considered and agreed upon. It is the common view on and basis for the process towards the required outcome. Moreover, it is not a feasibility study nor a business plan.

Roadmaps are applied in all kinds of business mostly for product development and technological innovation. In this study the focus in on food supply chains, implying some direction and focus in the approach. Typically, the methodology is used to change or innovate (parts of) food supply chains to serve some specific market(s) in a competitive way. In this context, two models from literature are used and integrated to construct a roadmap methodology. The structure of these models is the basis to describe the current and targeted situation and gives direction to the necessary activities. The first model is adapted from Van der Vorst [4]. It is a conceptual framework for supply chain analysis and is applied very often in agricultural/food supply chains. Since both opportunities in this study are focused on the national Ghanaian market also a model is introduced that offers an effective way for analysing the national competitiveness: the Porter Diamond model [5]. This model contains the elements that need to be covered in order to be competitive, and hence plays an important role in the roadmaps for tomato and mango.

\subsection{Food supply chain model}

The main difference between western economies and those in developing countries is the linkage between stakeholders in the food supply chain or network. Western economies are market driven and especially for perishable products like agricultural products, a lot of efficiency and food waste reduction can therefore be achieved. Developing countries in many cases still have push markets, where people like to buy fresh products from whatever is available on the wholesale market. Although trade relations and dependencies exist, formal contracts are scarce and in most cases, the power position in the food supply chain is not equally distributed. In the two business cases at hand the current supply chains typically are not well developed and connected. To achieve the goals as described in the vision a supply chain approach is required. 
In the nineties, the shift from optimizing companies to supply chains was made and a new framework to do so was introduced in 2000 by Van der Vorst. The rationale behind this model is that logistics in a supply chain are driven by market requirements and product characteristics. The performance of the supply chain should comply with these issues and whenever this is not the case or the market is, changing the supply chain should be redesigned. A visual of this idea is shown in Figure 1:

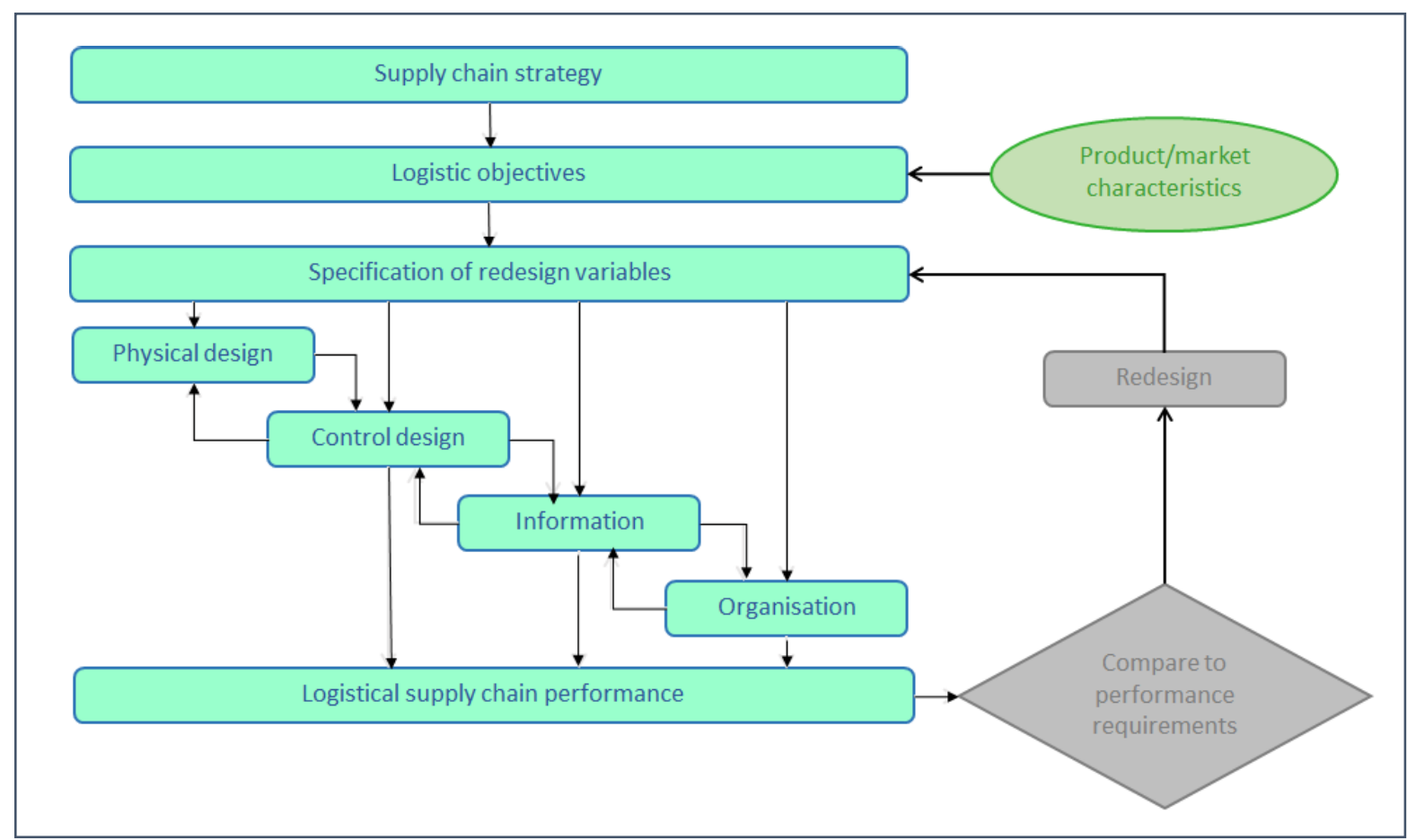

Figure 1: Conceptual framework for supply chain analysis (Source: Van der Vorst)

There are four types of design variables in this model:

- physical design

- control design

- information

- organization

Definitions of these types are from [4]:

Physical design: refers to the set of participants with specified roles in the supply chain and the required infrastructures defined at three levels: network design, facility design, and resource and product characteristics. Network design concerns decisions on the supply chain partners to be chosen and the roles they are to perform. Facility design refers to facility layout and location, process type and (geographical) location of stock points. 
Control design: the logistic control concept plans, controls and co-ordinates business processes in the supply chain while aiming at realising logistical objectives within the restrictions set by the supply chain configuration and strategic supply chain objectives. It can be described by four elements: hierarchy in decision levels, type of decision-making, position of the CODPs ${ }^{2}$ and level of co-ordination.

Information: The control system takes decisions based on information and generates control actions. In most Western countries, this information exchange is automated. This is a consequence of having relatively stable relationships and standards. Automated information flow is not targeted for the supply chains at hand. Information is though, and three types are relevant:

- market information

- transactional information

- analytical information

Organization: organization comprises two main elements: the establishment of tasks and coordination of those tasks in order to realise objectives. Hence, the organisation structure is closely related to the control design since it facilitates, together with the information system, the coordination of activities.

Typical elements in the food supply chain structure are:

\begin{tabular}{|c|c|}
\hline Physical design & Control design \\
\hline 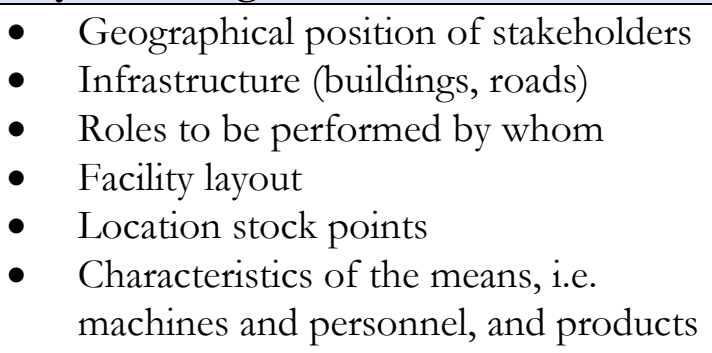 & $\begin{array}{ll}\text { - } & \text { CODP } \\
\text { - } & \text { Lead time } \\
\text { - } & \text { Organize information flows } \\
\text { - } & \text { Set up training }\end{array}$ \\
\hline Information & Organization \\
\hline 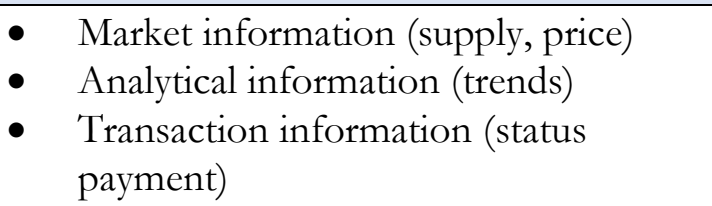 & $\begin{array}{l}\text { - } \quad \text { Coordination of tasks } \\
\text { - Linkages vertical and horizontal in supply chain } \\
\text { - Decision making }\end{array}$ \\
\hline
\end{tabular}

Table 1: Elements related to the various parts of the supply chain structure

These elements do not elaborate on crucial issues like (inevitable) circumstances or competition. Hence, the Porter Diamond model from M.E. Porter is added, where these themes are included. Note that the market is an external force in de Van de Vorst model; however, the relevant market

\footnotetext{
${ }^{2}$ Customer Order Decoupling Points
} 
characteristics are not mentioned. Here also the Porter Diamond Model is extending the basics to some point.

\subsection{The Porter Diamond Model}

This economic model for (small-sized) businesses is developed to help them understand their competitive position. Michael Porter assumes that the competitiveness of businesses is related to the performance of other businesses. Furthermore, other factors are tied together in the valueadded chain in a long distance relation or a local or regional context. He uses the concept of clusters of identical product groups in which there is considerable competitive pressure.

Businesses within clusters usually stimulate each other to increase productivity, foster innovation and improve business results. In particular, for the two cases at hand there is competition on a regional level. Not only between Burkina Faso and Ghana, but also between fresh versus processed market, and regional small and medium-sized processors in Brong-Ahafo and Ashanti as is identified as an opportunity. After all, decentralization will decrease logistic costs and the need for large volumes of tonnes per day that were required for Techiman and Wenchi.

The Porter Diamond Model (=PDM) bases its assessment on six elements:

- factor conditions

- demand conditions

- related and supporting industries

- firm strategy, structure and rivalry

- chance

- government

All elements are related with one another except for the government and chance (see Figure $2^{3}$ )

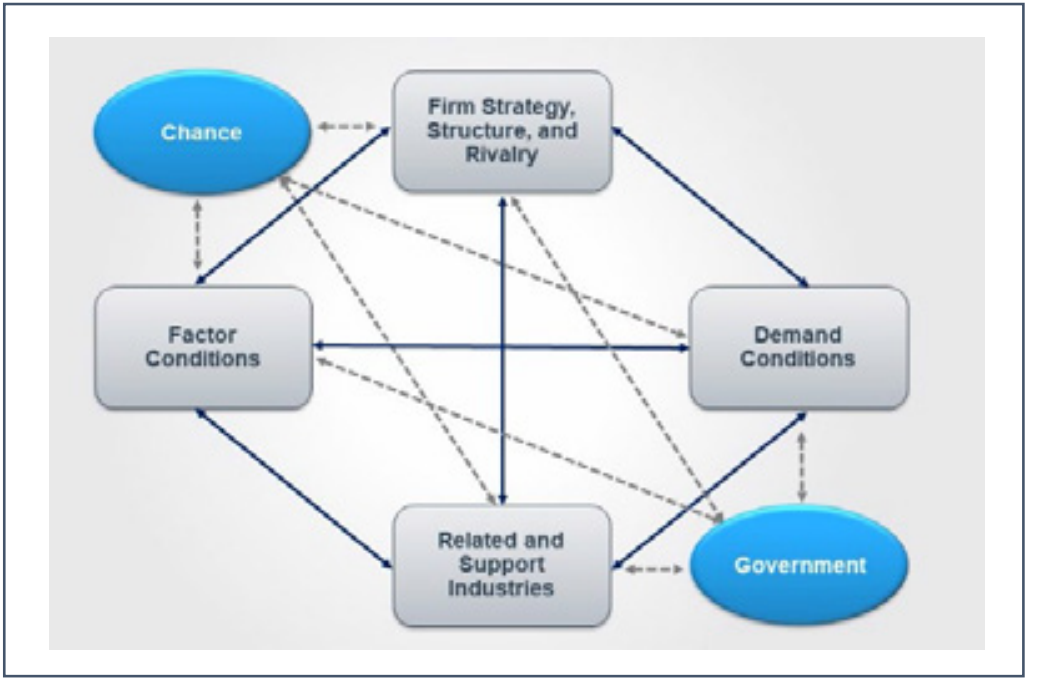

Figure 2: Porter Diamond Model

\footnotetext{
3 https://www.toolshero.com/strategy/porter-diamond-model/, viewed 21-5-2018
} 
Factor conditions: Factor conditions are the first element of the PDM. They refer to different types of resources that may or may not be present in the region: human resources, physical resources, knowledge resources, capital resources and infrastructure. One can make the distinction between basic and advanced factors. Basic factors include natural resources (climate, minerals, oil) where the mobility of the factors is low. Although these factors may create the ground for international competitiveness, they can never turn into real value creation without the advanced factors. Advanced factors are more sophisticated, such as human resources (skills) and research capabilities. They are normally specific to the industry.

Related and support industries: The success of a market depends on the presence of suppliers and related industries within a region. A critical concept here is that national competitive strengths tend to be associated with 'clusters' of industries. For example, Silicon Valley in the USA and Silicon Glen in the UK are techno clusters of high-technology industries, which includes individual computer software and semi-conductor firms.

Demand conditions: Demand conditions in the domestic market provide the primary driver of growth, innovation and quality improvement. The premise is that a strong domestic market stimulates the firm from being a start up to a slightly expanded and bigger organization. In this determinant the key question is: What reasons are there for a successful market? What is the nature of the market and what is the market size? There always exists an interaction between economies of scale, transportation costs and the size of the home market. If a producer can realize sufficient economies of scale, this will offer advantages to other companies to service the market from a single location. In addition, the question can be asked: what impact does this have on the pace and direction of innovation and product development?

Firm strategy, structure and rivalry: This factor is related to the way in which an organization is organized and managed, its corporate objectives and the measure of rivalry within its own organizational culture. National performance in particular sectors is inevitably related to the strategies and the structure of the firms in that sector. Competition plays a big role in driving innovation and the subsequent upgradation of competitive advantage. Since domestic competition is, more direct and affects earlier than steps taken by foreign competitors, the stimulus provided by them is higher in terms of innovation and efficiency.

Chance: Chance refers to random events that are beyond the control of the company. In most markets, chance plays an important role. It provides opportunities for innovative companies that are not afraid to start up new operations.

Government: The government can have strong influence on the competitiveness of a firm. It can influence almost all forces in the PDM. They can either promote or hinder export, influence the supply conditions of key production factors. It can shape the demand conditions in the home 
market, as well as the competition between firms. These interventions can occur at local, regional, national, or even supranational level. Moreover, governments finance and construct infrastructure (roads, airports) and invest in education and healthcare. They can encourage companies to use alternative energy or alternative environmental systems that affect production. This can be effected by granting subsidies or other financial incentives.

Although the PDM refers to Western countries, and strong competition is not a necessary condition for success, the concept can be related and if required adapted to less developed countries. This is done to some extent in the table below. It is still general, but with already a some focus on horticulture:

\begin{tabular}{|c|c|c|}
\hline Factor conditions & Related and support Industries & Demand conditions \\
\hline $\begin{array}{l}\text { - Skilled labour } \\
\text { - Land availability } \\
\text { - Production knowledge } \\
\text { - Financial resources } \\
\text { - Natural circumstances }\end{array}$ & $\begin{array}{ll} & \text { Seed supply } \\
\text { - } & \text { Other small-medium scale } \\
\text { - } & \text { Frocessors } \\
\text { - } & \text { Moreign investors } \\
\text { - } & \text { Technology level }\end{array}$ & $\begin{array}{ll}\text { - } & \text { Market size } \\
\text { - } & \text { Market growth } \\
\text { - } & \text { Preferences } \\
& \text { Innovation (new } \\
& \text { products) }\end{array}$ \\
\hline $\begin{array}{l}\text { Firm strategy, structure } \\
\text { and rivalry }\end{array}$ & Chance & Government \\
\hline $\begin{array}{l}\text { - Competition within the } \\
\text { region } \\
\text { - Level of organization } \\
\text { - Fresh versus processed }\end{array}$ & $\begin{array}{ll} & \text { Climatically variation } \\
\text { - } & \text { Political change/instability }\end{array}$ & $\begin{array}{l}\text { - Infrastructure } \\
\text { - Extension services } \\
\text { - Subsidies / tax incentives } \\
\text { - Policy }\end{array}$ \\
\hline
\end{tabular}

Table 2: Elements to be addressed in Porter Diamond Model

Note that the elements from both models are not disjunctive. They will be integrated in the methodology for the roadmap.

\subsection{Setting up the roadmap}

Based on the two previous models the roadmap structure is defined. The models provide the ingredients to build a methodology for the roadmap. All elements are reallocated to 6 categories that are strongly related to the categories from the models. This is elaborated in Appendix A. The methodology is supported by a conceptual view on the supply chain and the impact of external factors (see Figure 3). The approach is divided in 6 steps:

1. Ambition/vision: Start from the ambition/vision for the sector: based on previous reports and a workshop in Ghana target sectors and their ambition for the roadmap are identified

2. Market: Identify relevant market information on the sector (use elements of PDM): in general quantitative information on market size, growth and consumer preferences are 
collected together with a qualitative description about the marketing actors and their way of operation

3. Challenges: Describe the challenges in relation to the ambition/vision: challenges are well known from earlier phases in the project, mainly based on desk study and interviews with Ghanaian stakeholders in the particular sectors.

4. Relation to roadmap structure: Select relevant elements from the 6 categories in Figure 3 based on the main challenges identified (use) and include adjacent topics that need to be changed

5. Current and target situation: Describe the current and target situation of the supply chain in relation to these elements and the ambition

6. Activities and resources: Derive the required activities per element including order, dependencies and resources

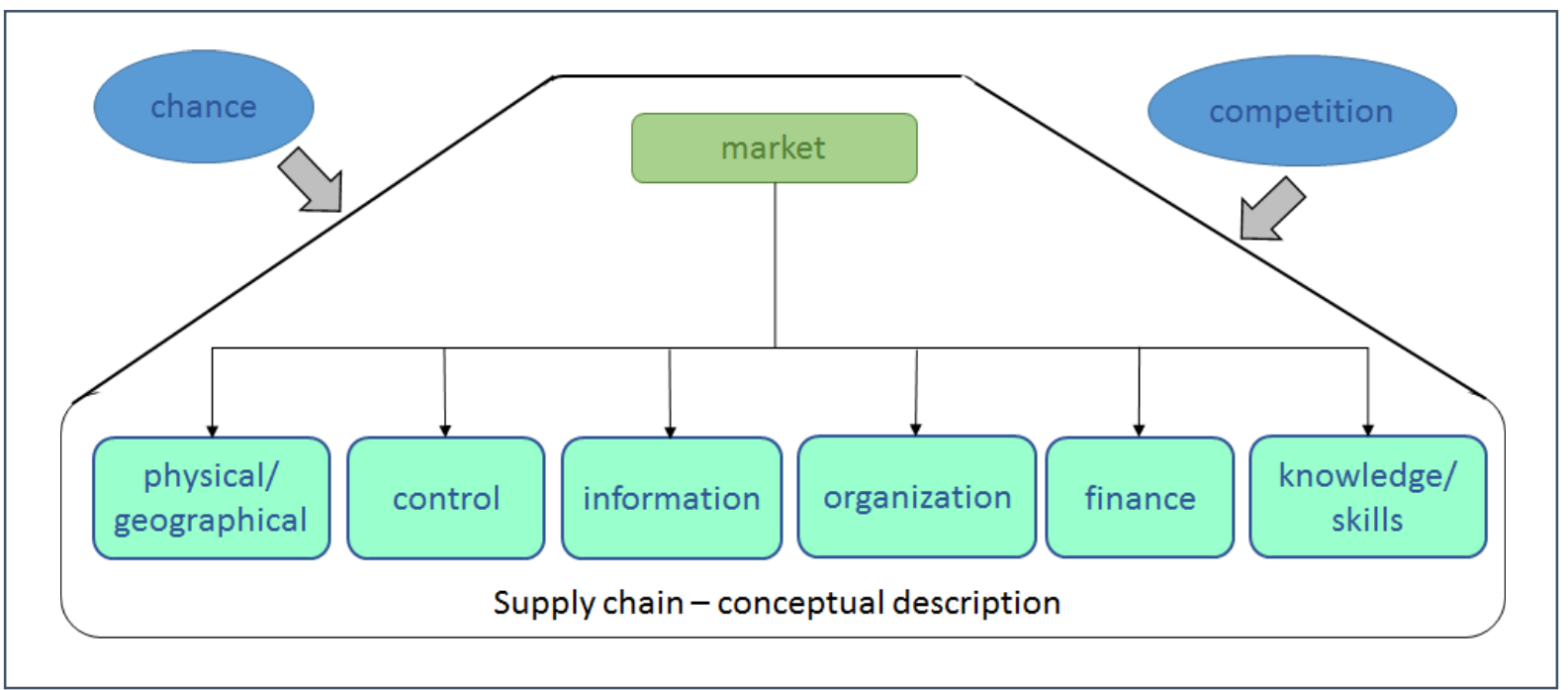

Figure 3: Conceptual description of the supply chain in its environment (Source: Wageningen Food \& Biobased Research)

The structure described above is used as a map to cover all the necessary issues for a plan to achieve the goals aimed for in the vision. In the chapters hereafter the steps in the roadmap are carried out based on this map for the tomato supply chain for processing in the regions BrongAhafo and Ashanti. 


\section{The tomato (processing) roadmap}

The roadmap methodology is applied to the tomato-processing sector in Ghana for the BrongAhafo/Ashanti region. The focus of the project is on post-harvest management; however, some issues on production are so important that they cannot be neglected. They will be mentioned but not elaborated in that much detail as the post-harvest topics.

\subsection{Step 1: Tomato processing sector ambition}

For the tomato chain, the ambition is to:

Boost the processing sector in the tomato production areas Brong-Ahafo/Ashanti region, not only on factory level (long term) but also on small and medium scale (short term).

The objectives are as follows:

1. Determine and suggest interventions to help small-, medium scale tomato processors in the short term;

2. To improve on the handling, packaging and transportation of "processed" tomato

3. Reduce post-harvest losses through the use of small-scale (cottage level) processing centres for tomatoes in local areas;

4. Improve the quality of processed tomato products for small and medium scale tomato processors;

5. Develop interventions to improve raw material handling and process control at all levels of the tomato processing chain.

The evaluation of the Ghanaian tomato industry chain also involves to a large part the assessment of the Ghanaian tomato-processing sector. The added value given by processing to tomatoes are invaluable not only from the economic point of view but in also in making sure that Ghanaian tomato industry is able to support changing local consumer preferences and are able to keep up with national and international challenges. More importantly, the Ghanaian tomato processors should play a big role in value addition of tomato produce to develop a sustainable and vibrant tomato industry. Thus, a roadmap for developing the tomato processing industry is important.

\subsection{Step 2: The market of tomato processing}

The current situation of the Ghanaian tomato chain is characterized as being heavily dependent on lead boys (traders for the market queens), intermediaries between the tomato farmers and various Ghanaian tomato markets. The lead boys control harvest and markets for fresh and processing tomatoes in Ghana. However, the lead boys' decisions are based solely on profitability. Whether the tomatoes are taken to the fresh market or taken to tomato processors is mainly a function of profits and margins. By extension, the fresh imports of tomatoes from Burkina Faso by Ghanaian lead boys is also economically driven. According to official statistics like UN Comtrade, these exports are about 12,500 tons of fresh tomato in 2016. Note that the 
estimated annual production of tomatoes in Ghana is 300,000 tons [6]. The market forces which plays within Ghana and the immediate environment is indicative of the structural reforms required for tomato processing in Ghana to be improved. For large-scale tomato paste production to be profitable, limiting input costs are essential. With the current market forces at play within the Ghanaian industry, the unstable supply of processing tomatoes, at appropriate quality and costs are prohibitive. Calculations made by Robinson and Kolavalli [7] projects that for large scale tomato paste production in Ghana to be competitive in the international market, a cost price of about $100 \mathrm{GH}$ per ton is required. However, local markets can command much higher prices than these for tomatoes. However, because market forces are also at play in local Ghanaian fresh tomato markets, an oversupply lowers the price. As a result, the short-term view on profitability causes longer-term economic losses not just for the tomato processors but also for all the other players in the chain.

Similarly, local Ghanaian tomato processors also face competition from imported processed tomatoes. This is because imported tomato paste producers are still able to compete even if there are added logistical costs and duties. Partly, this is also because changes in international trade rules opened the Ghanaian borders. However, the international competition is a reminder that the Ghanaian tomato processing industry needs to level off at international standard as well. In 2016, about 100,000 tons of tomato paste were imported of which about $75 \%$ were from China.

In the processing sector, large-scale processors are in the centre of news and attention from the government. They are crucial to the national economy in self-sufficiency but also employment and prosperity for the region. Based on evaluation of information available, large-scale tomato paste production in Ghana is not appropriate given the current situation of the Ghanaian tomato industry. A number of large-scale tomato processing facilities have closed down operations. Unless a steady supply of high quality and relatively inexpensive tomatoes are available for the large-scale processors, the tomato paste production in Ghana is unlikely to compete with international tomato paste production because of quality detractions. With this in mind, we focus on the small and medium scale food processors as a starting point in this roadmap. Additionally, focus is given in reducing post-harvest losses and in allowing a local tomato processing industry to thrive for the benefit of all the players in the Ghanaian tomato industry. To revitalize the large scale processing the small and medium processors can be used as the test case for the implementation of new steps in dimensions like e.g. variety, consumer preference, and functional design. This is a crucial consideration for the roadmap.

\subsubsection{Small/Micro level processors}

At the small/micro (cottage) level processing industry, the mill shop plays a central role in valorising fresh tomato over supply or glut in the Ghanaian market.

The mill shops serve both consumers directly but also significantly institutional clients (e.g. small restaurants and business). The mill shops facilitate conversion of fresh tomatoes in the market into freshly milled, tomato-based products (mostly sauces of local Ghanaian formulation/recipe). 
The product lines in mill shops are currently not identified. Their business serves as an intermediary modest processing centre for tomato. In most cases, clients come in with tomatoes

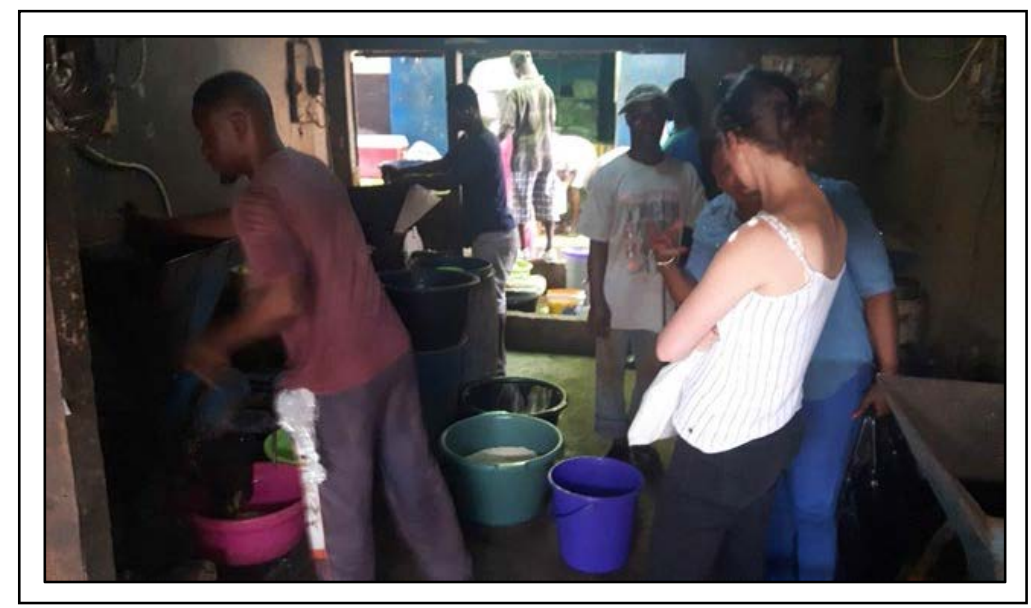

Figure 4: Mill shop at Makola market, Accra, 2018 (Photo: Jan Verschoor)

and other spices/condiments following their own specific formulation.

The mill shop facilitates the conversion of these ingredients into a fresh type sauce with minimal packaging, with no means of preservation applied. They do not use neither chemical (e.g. food preservatives) nor physical (e.g. pasteurization) preservation means. Preservation techniques is therefore an important technology that can drastically improve the operations and product lines at the small/micro level processing centres in Ghana.

The milled shops do not follow any standard processing techniques/procedure. Machines and processing techniques differ from one shop to the other. Quality systems and quality protocols are non-existent. There are also no quality checks from the Standards Development Authority, ensuring compliance to food safety and hygiene practices. Since this level of processing may account for more than $80 \%$ of local tomato processing industry in Ghana, it will require more investment, standardization of operation and monitoring by relevant institutions to ensure compliance to protocols. Intensive training will also be required for these processors.

\subsubsection{Medium scale tomato processors in Ghana}

A number of medium scale tomato processors in Ghana exists. However, most of these processors have closed down their operations. The prevailing reason for this is the high financial costs in operating the processing plant. This is partly due to the costs of raw material inputs, utilities, transportation and stiff competition from cheap imports [7]. However, the low product value (tomato paste) and the limited supply of tomatoes for processing also affect the throughput of the medium scale tomato processors.

Together, these factors make it difficult for medium scale tomato processors to obtain a viable commercial enterprise. In addition, medium scale processing plants who focus only on tomato processing are idle outside of the tomato harvest season. Thus, the productivity of medium scale processing plants are limited to only a quarter of the year. Prices of tomatoes increase by over $500 \%$ in between seasons, which shortens the supply period to all the processors. However, it is 
important to acknowledge that presently processing facilities and expertise on operating a medium scale tomato processing line is present in Ghana.

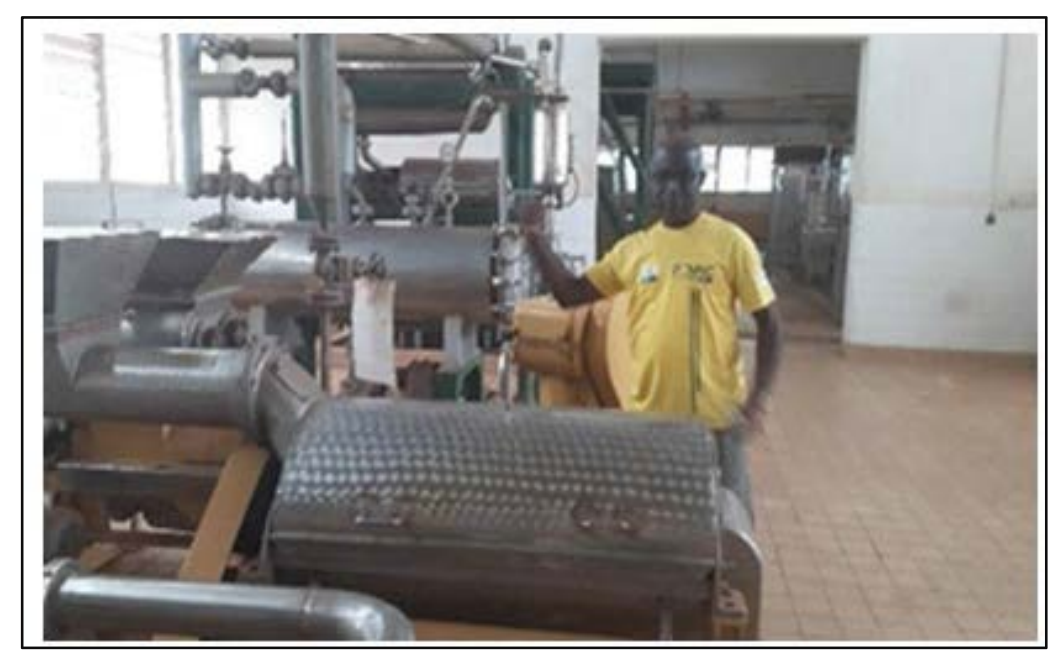

Figure 5: Mr Kwabena Adu-Gyamfi of Wenchi processing at their medium scale processing facility. Wenchi processing uses the same facility to process tomatoes and mangoes, 2018 (Photo: Jan Verschoor)

\subsubsection{Large scale tomato processors in Ghana}

Several large-scale tomato processing plants exists in Ghana. These large-scale processing facilities were built in cooperation with government and international programs. One such largescale tomato processing plant is Pwalugu Tomato Factory situated in the Upper East region of Ghana. The factory was renovated in 2015 at GHS50 million to produce in excess of 25,000 metric tonnes, which is almost 25 percent of the local consumption. However, due to difficulties in sourcing raw materials from out-growers and the factory's own farm, the plant in the Upper East has closed down and is currently on divestiture. Another contributing factor to the closing of the facility is the lack of reliable tomato supply from outside its operational area. There are also financial difficulties in maintaining the operating costs required for the large-scale tomato processing plants. The low priced imported tomato pastes make it difficult for the Ghanaian processed tomato products to compete locally. The higher costs of raw materials and operating costs also makes it difficult for Ghanaian processed tomato products to compete with imported counterparts. As with the medium scale processors, large-scale tomato processing in Ghana also only operates during the tomato harvest season. For the rest the year, the processing plants are idle. What worsened the plight of the factory was the unstable power supply that hit the country in some years back.

\subsection{Step 3: Tomato processing sector challenges in relation to the ambition}

The work of Robinson and Kolavalli [7] on their case study of the Ghanaian tomato processing industry as published for the International Food Policy Research Institute outlines important features and suggestions for improving the current state of the sector. In addition, the review of the tomato industry in Ghana by Baba et al. [8] also outlines the challenges and strategies they 
face. In both cases, it is clear that large-scale tomato processing enterprise in Ghana has so far failed to compete with international tomato paste producers. This have been mainly due to inconsistent and unreliable supply of tomatoes for processing, high post-harvest losses, noncompatible varietals, diseases in the soil and the lack of structural framework to strengthen the collaboration between farmers/growers, processor and fresh market players [9].

\subsubsection{Tomato varieties}

There are two major tomato varieties grown in Ghana. These are Power Rano and Cobra. The Power Rano is a farmer-developed hybrid that is suitable for the agronomic conditions in Ghana. Not much information is available for the Power Rano as far as its processing characteristics are concerned but has firm epidermal characteristics. On the other hand, the Cobra variety is an industry-developed cultivar, which possesses good resistance and gives high tomato yield. However, tomatoes coming from the Cobra variety is not ideal for tomato processing nor is it ideal for the post-harvest handling currently practiced in Ghana. The Cobra variety has high moisture content and low textural properties when fully ripe. They require careful handling so that the fruit remains intact (whole) during post-harvest handling.

In general, processing tomatoes should at the minimum possess two major characteristics. First, high solids content. Most tomatoes processed into paste requires concentration and removal of moisture. The industry standard for tomato juices for tomato paste production starts at 5 Brix level. This is then concentrated 5-6 times depending on the tomato paste requirements of the plant. Second, processing tomatoes need to have high textural properties to withstand material handling during mechanical harvesting, transport, washing, sorting. Bruised tomatoes are usually sorted out in the processing lines. Therefore using tomato varieties such as Roma and Pectomech among others will suit both the fresh market and process industry in Ghana. Both Roma and Pectomech varieties are available in Ghana. Table 3, adapted from [8] shows tomato varieties that have been evaluated in Ghana by the Ghanaian Ministry of Food and Agriculture (MoFA) and HJ Heinz International Company.

\begin{tabular}{|c|c|c|c|c|c|c|c|}
\hline Viniety & 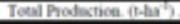 & $\operatorname{Bnax}$ & Find Weishin (z) & Venes & 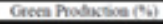 & Vinicy & Ros hodictiven (5) \\
\hline 184002 & 22.6 & & & V75 & 5.3 & 189314 & 3,2 \\
\hline Н 9382 & 26.7 & & & Н9476 & 11.3 & H9036 & $M .4$ \\
\hline Chise III & 27,3 & & & Penound & 12.2 & н 9665 & 3,4 \\
\hline В9144 & $2 \times 2$ & & & Claso III & 12.2 & 18945 & 3.8 \\
\hline Н 199 & 28.2 & & & H $\$ 002$ & 12.4 & H $19 \%$ & 4.0 \\
\hline vis & 29.3 & 3.4 & 71 & Н 1999 & 12.5 & Roena & 4.2 \\
\hline H 9491 & 30.1 & 3.5 & $\pi$ & Н 9314 & 13.7 & H914 & 4.5 \\
\hline H9LS & 30.6 & & & $\mathrm{H}$ tout & 13, & B9491 & 5.6 \\
\hline Pesoment & 31.1 & & & H 9382 & 16.1 & H 8892 & 3.6 \\
\hline H9478 & 31.3 & 3.6 & 57 & H 8892 & 183 & Petomesch & 8.1 \\
\hline Н 9715 : & 32.5 & 3.6 & ss & H7tsi & 19.6 & H 7151 & 8.5 \\
\hline H 7151 & 32.5 & 3.9 & 81 & Rowa & 21.7 & $\mathrm{H}+4002$ & 7,1 \\
\hline H 9865 & 32.6 & & & H9144 & 21.9 & Н 9383 & 8.5 \\
\hline 145392 & 32.4 & & & insol6 & 294 & VIs & 8.7 \\
\hline В 9553 & 34.2 & 3.5 & 55 & H 9491 & 24.1 & H9478 & 9.6 \\
\hline Rona & 3.6 & 3.4 & $\$ 8$ & H 9665 & 253 & H 3044 & 10.1 \\
\hline H9314 & 343 & is & $5 t$ & H945 & 275 & H925 & 11.6 \\
\hline H9036 & 36.1 & 3.5 & 6 & H9583 & $\$ 0$ & Casou & ists \\
\hline H 3044 & 361 & 3.3 & \% & & & & \\
\hline Average & 309 & & & Averape & 179 & Averaps & 6.7 \\
\hline LSD & 11.7 & & & $\mathrm{LO}$ & io.s & Lso & 8.5 \\
\hline sit & Teal holactica that. & & & sir & Ceces Prodaction ots & $\sin$ & Rot hodurisies: \\
\hline VEA & 27,5 & & & VE & 13,4 & VEA & 8.7 \\
\hline TONo & 343 & & & TONO & 22.4 & ToNo & 9.8 \\
\hline Averope & 309 & & & Averape & 179 & Averape & 87 \\
\hline LSD & & & & & is & 150 & 2.5 \\
\hline NOTE $\mathrm{L}$ & - Lower Sipaifican Diffe & & & & & & \\
\hline
\end{tabular}

Table 3: Varietals of tomato tested by MoFA and Heinz International 
Currently, the selection of tomato varieties planted in Ghana are heavily based on their agronomic characteristics. Tomato diseases in Ghana are mainly due to nematodes, fungal and bacterial infections are rightly addressed in selecting suitable varieties. However, the functionality of the tomato fit for purpose should not be overlooked. As mentioned above, desired processing tomato characteristics and current post-harvest handling practices should also go hand in hand when selecting tomato varieties.

\subsubsection{Stabilize tomato supply for local fresh and local processing markets}

Individual farmers do much of the tomato production in Ghana. Predominantly, the production of tomatoes for the fresh market and processing industry are not clearly separated. As a result, farmers and lead boys will sell their produce wherever they could command a higher price. In this scenario, the fresh market has an initial price advantage. However, as the tomato supply increases, the fresh market prices fall. This scenario has happened in Ghana ultimately resulting in tomatoes being left in the field, unharvested. Therefore, the importance of stabilizing supply for both the fresh and processing industry are important. Many specific proposals on how this can be done effectively have been forwarded. Some examples of these proposals include separation of the fresh and processing tomato supply, dedicated fields for processor, among others.

Other factors play a role in stabilizing the tomato supply. One of these factors involves increasing the yield of tomato production in the fields through the selection of appropriate tomato varieties and enhancement of agronomic practices. Numerous tomato diseases have affected the Ghanaian tomato farmers and rightly, the selection of varieties that are able to withstand these are important. The rain fed conditions of the tomato growing areas in Ghana also has an impact on tomato yields. Therefore, this should also be managed either through development of an irrigation system or through the selection of tomato varieties able to cope with existing rain-fed conditions.

Now, efforts to maintain large and medium scale tomato processing plants in Ghana have commercially failed. Considering the lack of organization within the Ghanaian tomato growers, it is also difficult to determine the appropriate production capacity with which a tomato processor should operate in (cottage/small, medium or large capacity). Furthermore, one of the first requirements for Ghanaian tomato processing industry is to identify how much reliable tomato supply might be available for processing. Currently, tomato processors need to compete with lead boys in obtaining tomatoes for their needs. If the Ghanaian tomato growers can stabilize supply for various tomato outlet (processing or fresh market), then medium (and perhaps even large) scale processors are also able to operate during the harvest season at their peak capacity.

As a direct consequence of the scenario shared in bullet 3.3.2, it will be prudent to organise the tomato farmer front into Farmer Based Organisations in other to take advantage of existing mechanisms of support. This will help in developing programmes to shore up existing 
production levels and to apportion by quantity and moral suasion what should go for the fresh fruit marketing and processing

\subsubsection{Improve raw material handling and process control for tomato processing at all levels.}

The implementation of improved raw material handling starting from the improvement of agronomic practices and on the establishment of a post-harvest best practices for tomatoes should help alleviate post-harvest losses. The improved raw material handling through the tomato chain in Ghana should also be extended on how tomatoes are sorted, stored and transported to end markets. Currently, farmers only harvest tomatoes when lead boys come to their farms. This should be changed so that the farmers have an independent facility to continuously harvest, sort, package, and store their tomatoes for intended markets.

Process control for tomato paste production and other processed tomato products are also important to maintain high quality standards. While instrumentation of equipment may help in this regard, implementation of quality control systems and quality assurance systems along all unit operations are essential. International quality certifications are necessary if the focus for the processed tomato products are for international export trade. However, most of these international quality certifications are based on best practices. Therefore, the initial focus for the processed tomato industry should be in establishing best practices for all unit operations. Within the facility, storage might be an option to decrease the dependency of the market queens. Although tomatoes can be stored 2 weeks on average, this might be an option due to strong price fluctuations and daily change in demands from the various stakeholders.

\subsubsection{Develop/propose a diverse portfolio of value added tomato products for the local Ghanaian market}

The tomato season is 3 months long, which is not enough to have a profitable processing facility. One of the ways to solve that is to process tomatoes at relatively low prices to the semi-product tomato paste. This can be stored a processed further according to consumer preferences. The challenge is to find out what kind of added value tomato products are marketable.

\subsubsection{Standardization and training}

Quality systems and quality protocols are non-existent in the processing industry in Ghana. It will require more investment, standardization of operation and monitoring by relevant institutions to ensure compliance to protocols. Intensive training will also be required for these processors.

\subsection{Step 4: Relation to roadmap structure}

The structure shown below is used to connect the findings related to the tomato-processing sector with the roadmap. The elements that are of importance to the sector are further mentioned below 


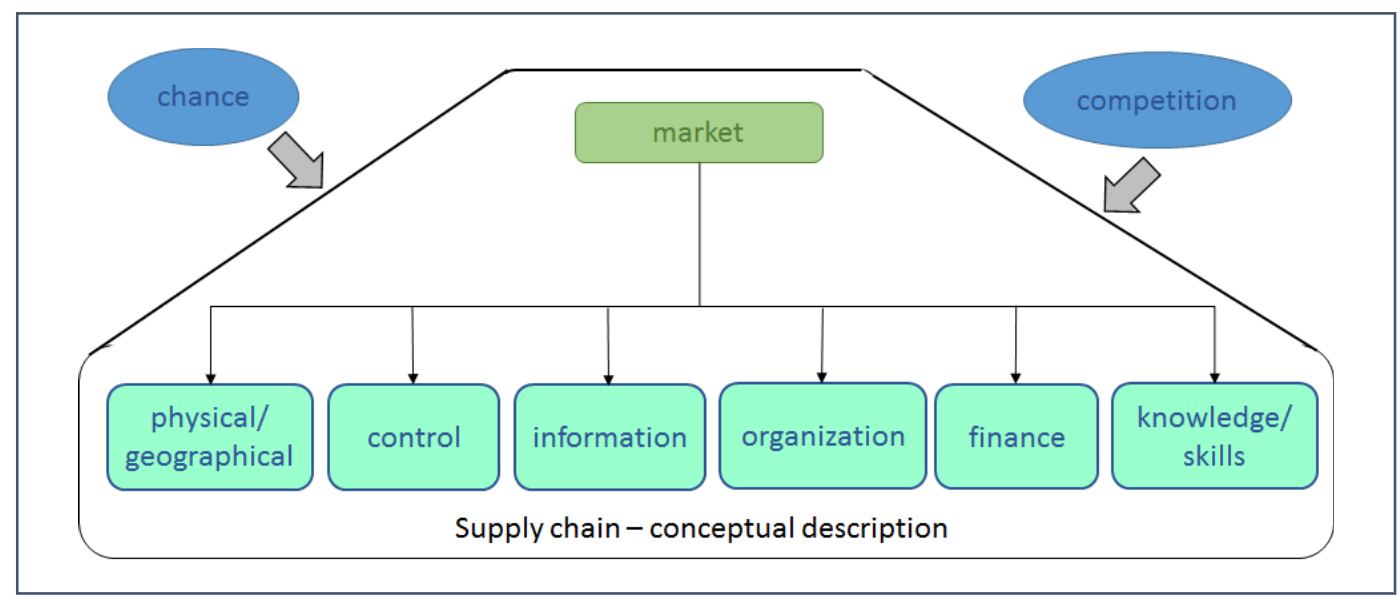

Figure 6: Conceptual description of the supply chain in its environment (Source: Wageningen Food \& Biobased Research)

\subsubsection{Tomato varietals}

The variety of the tomato is relevant for various stakeholders, and therefore is related to more than one element of the roadmap structure. In itself, the variety is a characteristic of the means, in particular the product, which is a part of the physical/geographical category. One of the adjacent elements that affect the variety are market preferences (category 'market') like taste, colour and firmness for the consumer, or brix for processing. In addition, disease resistance plays an important role since the soil in the Brong-Ahafo/Ashanti region contains diseases (category physical/geographical (natural circumstances)).

Physical/geographical: characteristics of the means, the product variety itself

Market: market preferences

Physical/geographical: natural circumstances (soil)

Knowledge/skills: $\quad$ production knowledge (other production methods to avoid diseases)

\subsubsection{Stabilize tomato supply for local fresh and local processing markets}

Continuity of supply is crucial in processing. If products are suited for storage, very often processors keep stock for at least a few days to keep the machines from becoming idle. Adjacent topics are the competition with the fresh market. In general, fresh market tomatoes bring higher profits than processing tomatoes, except during gluts. Hence, the volatility of the market price for tomatoes gives rise to much uncertainty on the supply side, which causes big economic losses on the processing side. In addition, competition from the lead boys and market queens is essential, since these actors have strong market power and source in competition from Burkina Faso. 
Another option for extending the production schedule is by using the existing processing lines for other fruit and vegetable commodities. Fruits like pineapple, pawpaw's, papaya can also make use of the tomato processing lines for the production of juices.

Another relevant issue is the fact that the tomato production in the regions Brong-Ahafo/ Ashanti is rain-fed. Uncertainty with respect to climate influences also leads to unstable supply.

$\begin{array}{ll}\text { Control: } & \text { organize input flows } \\ \text { External: } & \text { competition (fresh, lead boys/market queens) } \\ \text { External: } & \text { climate }\end{array}$

\subsubsection{Improve raw material handling and process control for tomato processing at all levels}

Food losses occur in the early stages in the supply chain. Improving handling in combination with sorting and packaging enables the farmer to shift his output to the appropriate markets and become less dependent on the lead boys. Adjacent themes are the organization of farmers in order to get microcredits and increase efficiency by using the scale. At a later stage, when quality becomes strongly related to price, quality measurement technology could be implemented.

Physical/geographical: facility layout (value adding activities)/roles to be performed by whom Finance: microcredits

Physical/geographical: technology level

Physical/geographical: facility layout (storage)

\subsubsection{Develop/propose a diverse portfolio of value added tomato products for the local Ghanaian market}

During the glut, many tomatoes can be processed into tomato paste, which can be considered as a semi-product. Once in stock the paste can be used during the off-season period to make added value products.

$\begin{array}{ll}\text { Market: } & \text { consumer preferences } \\ \text { Market: } & \text { innovation }\end{array}$

\subsubsection{Standardization and training}

To gain market access food safety and food quality are relevant issues as well as the continuity thereof. The Standards Development Authority and government are crucial in setting this up.

Government: extension services 


\subsection{Step 5: The current and target situation}

\subsubsection{Tomato Varieties}

The current varieties are presented and turn out not to match the preferences of neither the consumers nor the processors. Moreover, not many are resistant to diseases that are present in the soil in the Brong-Ahafo/Ashanti region. In the target situation varieties need to be grown that fit the market demand (fresh and processed) and where production does not suffer from diseases.

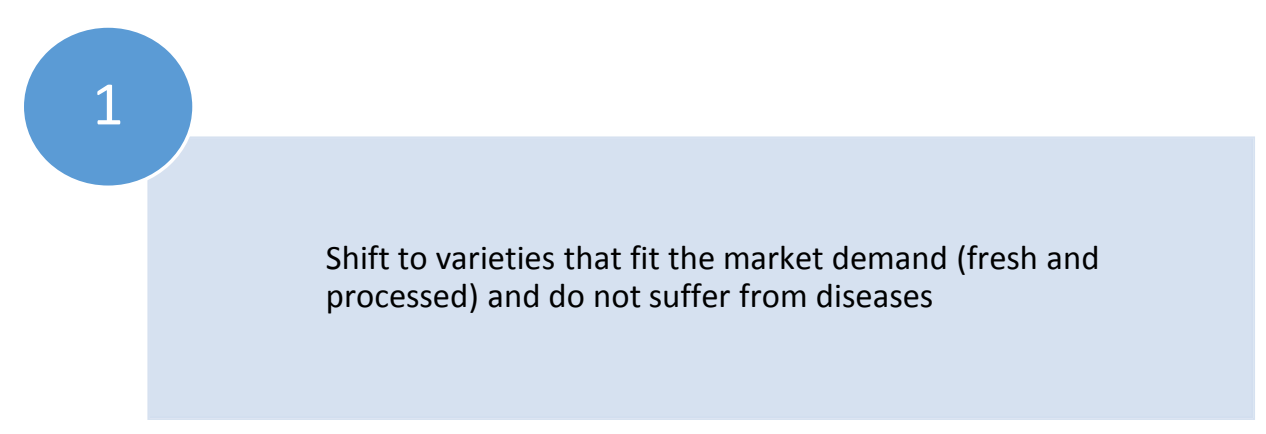

\subsubsection{Stabilize tomato supply}

In the current situation, there is no regulated or contract-based supply in significant volumes. For processing, at whatever scale, some basic minimal flow is required to have a profitable business. In the target situation, production should be attached to medium-scale processing on the short term and large scale for the long term. The small scale processing will remain local-to-local ad hoc business, where not much investment is needed for equipment.

In addition, structures need to be found to compete with the power of the existing market forces. Dependency on (advance) payment, inputs (seed, fertilizer...) should be reduced from the market queens by arranging these things locally.

The target situation should also be less climate or season-sensitive.

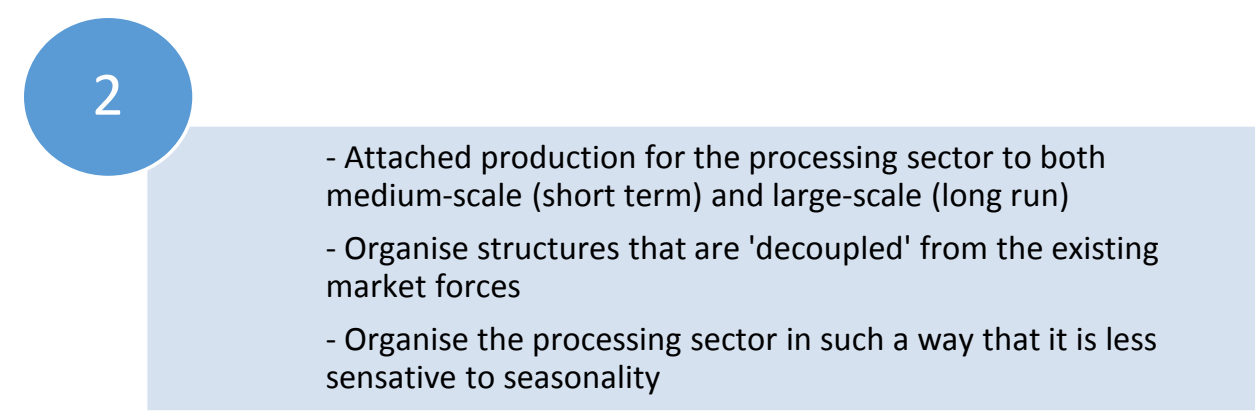




\subsubsection{Improve raw material handling and process control for tomato processing at all levels}

Tomatoes produced in the region are not predestined for a particular market. Varieties and qualities are mixed, which is logical because of the small scale of the farmers and lack of uniformity in product and production methods.

In the target situation handling like sorting and packing ads value that will not only reduce losses during transport but also because of a better match of product characteristics with the target market.

To achieve a local logistic facility financial support is required. In the new situation an organizational structure should be arranged where micro-credits will enable the first steps towards adding more value to the tomato supply chain. Not only processing, but also storage might be feasible. In case of strong price fluctuations, speculation and flexibility towards fresh or processed markets might be very profitable. At a later stage, when handled flows are increasing in volume, technology can be implemented to reduce logistic costs.

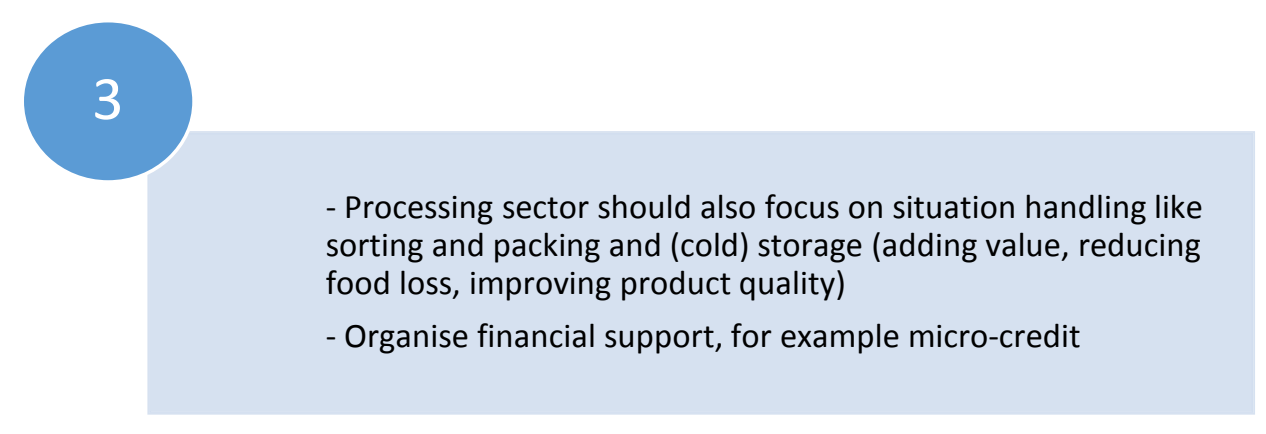

\subsubsection{Develop/propose a diverse portfolio of value added tomato products for the local Ghanaian market}

The Ghanaian market for tomato products is not very extensive. Consumers like to have some kind of paste and mix it (mostly at home) with other food ingredients to their own preference. Earlier consumer research [10] showed that canned tomato and ketchup are accepted, but dried tomatoes (except in the northern regions) and tomato juice are not popular. More options need to be explored.

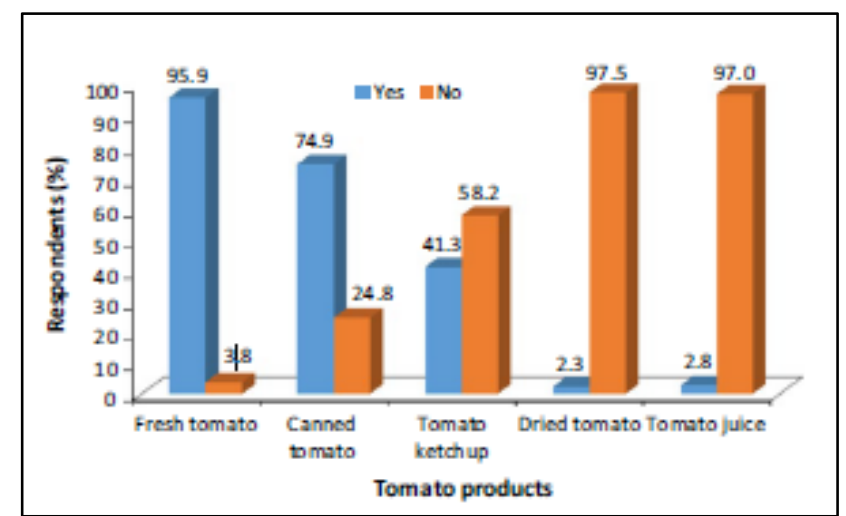

Figure 7: Consumer preferences for tomato products in Ghana [10] 
The development of value added tomato based products for the local Ghanaian market in the target situation will ensure that processing plants are commercially viable and that they are able to compete with the influx of imported tomato pastes. In addition, the value added processing also helps alleviate post-harvest losses both from the grower side and from the fresh market side. Some value added products from tomato pastes include their conversion into various tomato sauces (pasta sauce, ketchup, tomato soup, tomato-based marinades and barbecue sauces).

During the tomato harvest glut, processing plants can focus on the production of tomato paste mainly and other tomato products such as canned peeled whole and diced tomatoes, and semidried tomatoes. However, the specific value added products for the tomatoes should be specified to the processing operation scale.

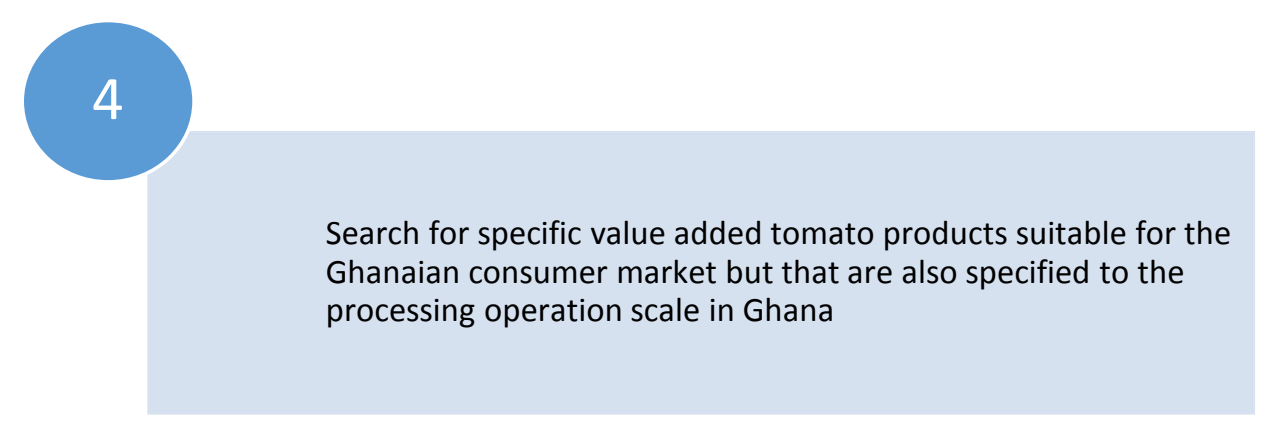

\subsubsection{Standardization and training}

In the current situation, the processing industry is highly fragmented and there is no coordination about standardization of processes. This is less relevant for the local consumer but is crucial to develop other markets that require a certain level of uniformity and scale. Since new markets are the drivers to growth and professionalization these requirements on standardization and quality are necessary and these activities will turn out to be self-supporting whenever value added markets are reached. Once processors can extend their market farmers will profit as well.

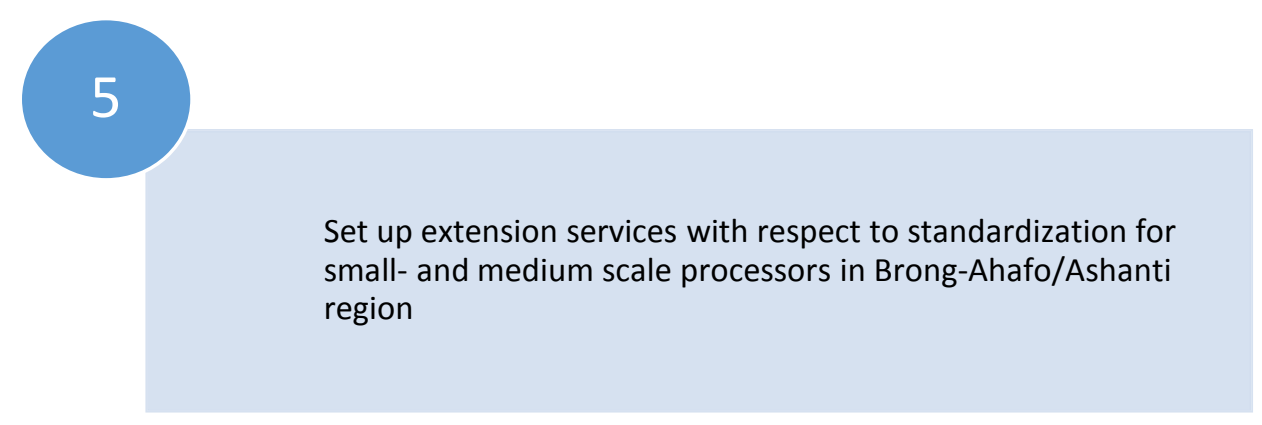




\subsection{Step 6: Activities and resources}

\subsubsection{Tomato varieties}

Activity 1.1: Based on earlier tests from Heinz and MoFA a restricted list of max 5 varieties should be tested. First of all, on consumer preference and second on required characteristics for processing at the various scales. The optimal situation is when a variety can serve both markets, in which case the glut for fresh produce automatically leads to large supply to processors. Activity 1.2: Either the varieties are tested on disease resistance as well or production knowledge is applied to grow tomatoes not on soil but on substrate in some kind of greenhouse. Currently a project on tomatoes is running in the Brong-Ahafo/Ashanti region to tackle the issues of diseases ${ }^{4}$.

Remark: in fact this is a pre-harvest issue and hence not a part of this study. However, the urgency and relevance of this matter is so high, that it cannot be omitted in this roadmap.

\subsubsection{Stabilize tomato supply}

Activity 2.1: The expansion of greenhouse production (eventually on substrate) and irrigation, including the knowledge transfer on production, will increase the yield on the one hand and reduce the losses on the other. Start up with pilot greenhouses and use the results from the other tomato greenhouse project in Brong-Ahafo region, mentioned earlier.

Activity 2.2: Starting small scale, applying proven technology should reduce the threshold for banks to provide (micro-)credits. In collaboration with MOTI and/or MoFA such a production site could be a trigger to set up business like this for other products. These stakeholders together should set up the financial structure to build such a production site.

Activity 2.3: Farmers need to organize themselves to compete with the market queens. A way to do so would be to connect them to the pilot site, where they can profit from production knowledge, microcredits and inputs. In first instance, it could be an option for the site to market themselves and give the farmers a share, until they are experienced or large enough to produce tomatoes on their own, eventually still linked to the pilot site (inputs, fertilizers...).

\subsubsection{Improve raw material handling and process control for tomato processing at all levels}

Activity 3.1: Investigate the feasibility of a logistic facility. Select a tomato production area in Brong-Ahafo/Ashanti and start collecting statistics about volumes, varietals, number of farmers and acreage. Analyse what functions could be relevant in a logistic facility: washing, (transport) packaging, storage, sorting... It is important to what market(s) such a facility can relate to avoiding the influence of the market queens. It might be just local to start with.

\footnotetext{
${ }^{4}$ Contact person: Anne Elings (Wageningen University Research)
} 
Activity 3.2: at a later stage, when the facility is more developed, technology might be implemented to reduce the operational costs

\subsubsection{Develop/propose a diverse portfolio of value added tomato products for the local Ghanaian market}

Activity 4.1: The value added processing of tomatoes should include:

a. Ghanaian small/cottage level processer (so called Mill shop)

i. The mill shops current serve as a mechanism to minimally process over supply from the Ghanaian fresh market.

ii. This should be extended so that tomato growers could also collaborate or reach mill shops to add value to oversupply of tomatoes at the farm level.

iii. Improvement of the mill shop operation by extending their food processing capabilities is important. Training on basic food processing hygiene and sanitation by quality institutions like the Ghana Standards Authority (GSA) is essential to upgrade the current mill shop operations. Training on basic food preservation with a focus on tomato-based products will improve the quality of products processed at the mill shop level.

iv. Basic food processing technologies such as pickling, bottling, pasteurization are important to formalize the mill shop operation. Since these are cottage scale industries, mill shop should cater at the local community level.

b. Small- and Medium scale tomato processor already present in the agro-logistic areas

Activity 4.2: However, instead of constructing new small- and medium- scale processing facilities, focus should be given to improve the operation of already existing processing plants in the agrologistic tomato growing areas. This is advantageous for a number of reasons. First, the fixed capital already exists in these areas (e.g. food processing infrastructure, tomato-processing lines/equipment). Second, human resources already trained in fruit and vegetable processing also exists. Focus on assisting these existing processors in making their operations commercially successful is critical. This requires training for management of a food processing enterprise and expansion of value added product lines. In the short term, focus should be given in improving value added tomato products for the Ghanaian local market by diversifying the product portfolio of the tomato processing chain. In addition, the focus should also be in assisting cottage-, smalland medium scale tomato processors instead of large scale tomato processing. Furthermore, the role of the cottage level tomato processors, so called mill shops should be extended as a means of preventing post-harvest losses at the farm and fresh market. At the same, the time role of the mill shops as a processor for the oversupply of tomatoes on the fresh market should also be strengthened by extending their processing capabilities and establishing minimally processed tomato-based products (bottled, pickled, pasteurized tomato products). However it is crucial to have market feedback on consumer preferences (local and in urban areas) before certain technologies should be applied. 
Knowledge transfer in terms of food sanitation practices should remain one of the high priorities at the micro/cottage level tomato processing. Especially since most mill shop, operations are based on minimal processing. Next to this, food preservation techniques (such as pickling, pasteurization, and bottling) should also be extended to mill shops so that they can make their own shelf stable minimally processed tomato products. In addition, food processing equipment and unit operations should be provided to mill shops so that their operations may be improved further. Cottage level processing centres should be equipped with small-scale kitchen equipment such as food processors, blenders/homogenizers, cookers/steamers, among others. For mill shops to have their own product lines, practical ways to improve food packaging and labelling should also be an important training target. Lastly, capital investment not just for equipment but also to extend mill shop business should be established to help these food processors increase production and use over supply of tomatoes.

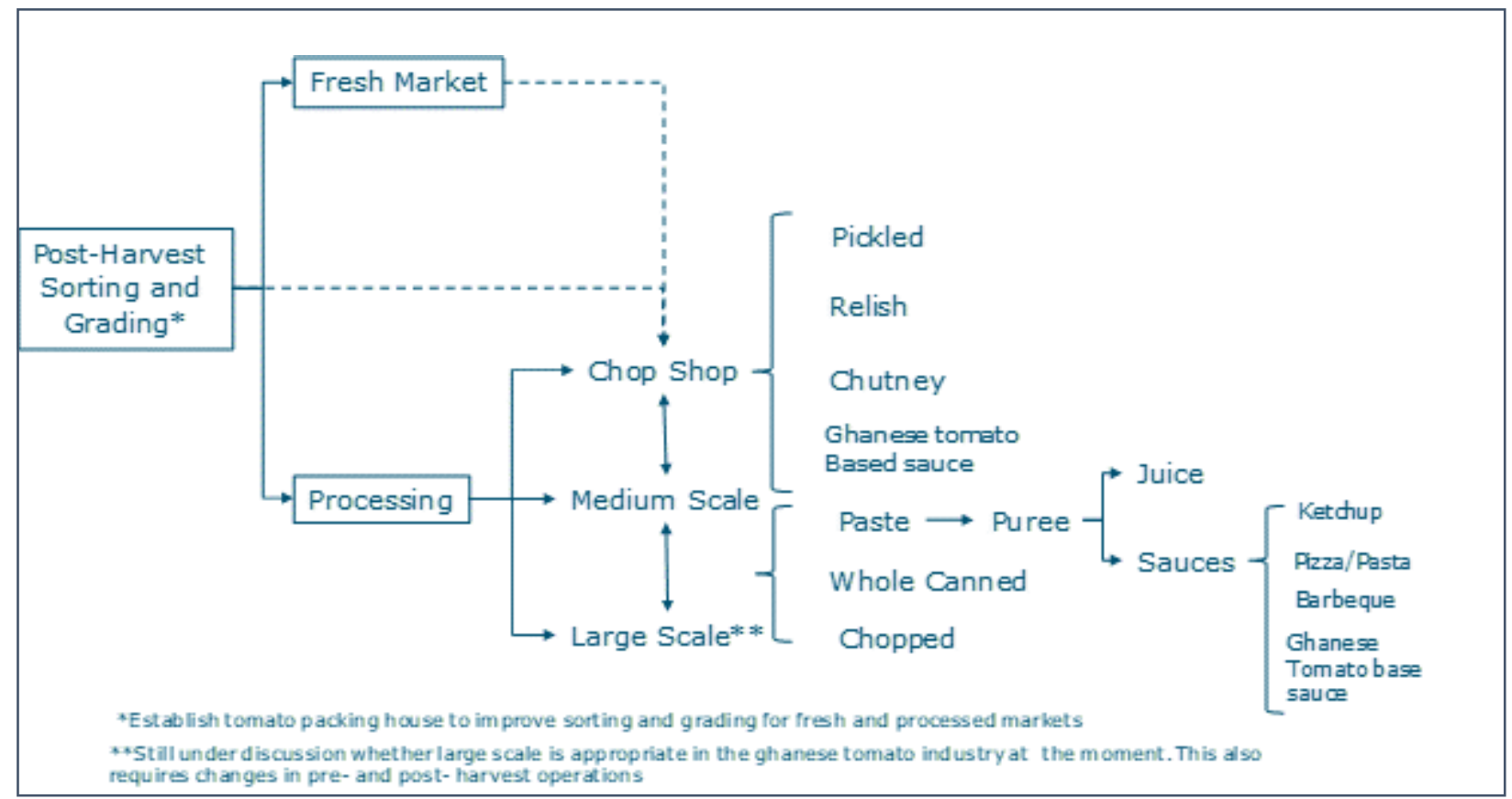

Figure 8: Proposal for value added products for the Ghanaian tomato processing industry (Source: Wageningen Food \& Biobased Research)

\subsubsection{Standardization and training}

Activity 5.1: the best way forward to support the region Brong-Ahafo/Ashanti is to select a few sub regions where small-scale processors can be found that are willing to comply with the standardization process, and farmers can be found that supply tomatoes free from diseases. These groups should be trained and supported towards standardization in processing. These front-runners can become the local 'extension service' by training the trainer and some financial support that is much more cost effective than government extension service. 


\section{The mango roadmap}

The roadmap methodology is applied to the mango supply chain in Ghana for the Brong-Ahafo and Ashanti region. The focus of the project is on post-harvest management, however some issues like on product availability will be mentioned but not elaborated on in detail like the postharvest topics. Thus, this chapter describes the so-called 'mango roadmap' based on the overall vision of the project (see paragraph 1.1.3) and based on the preparatory studies and workshops and aligned to the roadmap methodology.

\subsection{Step 1: Mango supply chain ambition}

Fresh fruit and vegetables are highly perishable crops. As such, shortening the time between harvesting and getting them to market and consumers is very important. However, in reality loss of fruit and vegetables products occur at every stage of the chain. Especially without the proper logistical infrastructure such as cold chain, appropriate post-harvest handling and suitable storage facilities, among others, it can be quite difficult to minimize loss of products and at the same time maintain high quality standards. Even with the infrastructure in place, cost may be prohibitive if operations are not efficiently and effectively managed. As such, the logistical issues involved in fresh fruit and vegetable marketing are key factors that could determine success of a commercially viable agricultural enterprise.

Another way of prolonging the marketability of perishable fruit and vegetable produce is through food processing. If done correctly, food processing will have minimal impact on fruit and vegetable organoleptic and nutritional properties while keeping high consumer acceptability. It allows for otherwise highly perishable fruit and vegetables to be marketed for longer times at farther distances. As such, food processing plays an important factor in bringing highly perishable fruit and vegetables to market.

For the case of the mangoes grown in Ghana, the fresh market plays an important role within the mango chain. Fresh mangoes at the peak quality can command high prices both in the local Ghanaian fresh market and in the international export market. Ghanaian mango growers already recognize this. Over the past few years, the land dedicated to mango growing has increased. In 2014, the Ghanaian mango production was estimated to be at about 99,000 metric tons ${ }^{5}$. The area dedicated to mango cultivation and growing spans about 7,500 hectares. Mango cultivation and production in Ghana is continuously increasing in the past few years due to governmental efforts and program that support the industry (i.e. Ghanaian Ministry of Food and Agriculture and Ghana Export Promotion Authority, among others). These mango farms are primarily located in the Brong-Ahafo, Ashanti and Northern regions [11]. In Southern Ghana, a number of commercial mango companies are located. Overall, the Ghanaian mango industry is poised to meet the growing local and international demands for fresh and processed mangoes. However,

\footnotetext{
${ }^{5}$ http:// wnw.fao.org/faostat/en/?\#data, viewed 1-6-2018
} 
there are certain challenges that face the Ghanaian mango industry. The combined effects of poor agronomic practices, lack of post-harvest facilities result in higher production costs and limited high quality fresh and processed mango products. It is estimated that about $20-50 \%$ of mangoes are lost during post-harvest handling in Ghana. Furthermore, of the mangoes that survive post-harvest handling, only $20-25 \%$ are graded as premium mangoes suitable for the export market. The remaining mango fruits are sold locally to either processors or to the local market and through intermediaries known locally as market women. This combination of low quality, high production cost, limited market opportunities are issues that need to be addressed so that the Ghanaian mango industry can successfully compete with their Western African neighbours, and beyond for both the local Ghanaian and international mango export markets.

The above mentioned and the research in the preparatory study (Phase 1: selecting product market combinations and possible interventions) show that reducing food losses and improving food quality should put a focus on aspects like clustering and consolidating, cold chain management, climate controlled transport, improved storage facilities, product handling and packaging, education and training regarding good handling practices, et cetera.

Therefore for the Ghanaian mango supply chain it is suggested to put a facility within the supply chain to achieve benefits for the whole value chain. The basic thinking is that establishing such a facility or hub strengthens the professionalization in the value chain in the following way. Increased level of organisation and trained producers and staff of the centre allows for efficiencies at harvest and post-harvest level. The hub also allows for increased product quality and quantity, which comply with the minimum food safety standards. If this is functional, eventually markets are better served and new markets created. To make a difference in the current mango industry in Ghana the post-harvest intervention should focus on small/medium scale processing as one of the major services the hub can provide. In this, these facilities can be seen as a combination of a Fresh Fruit Hub and a Small-scale Intermediate Processing Centres (SIPC) in mango catchment areas or clustered areas.

In summary, this amounts: 'To create within the production areas a bub that can offer various services such as handling, storing, packaging, processing and training'.

Derived from this challenge the ambition for the Ghanaian Mango Supply Chain is: production regions. 


\subsection{Step 2: The market for fresh and processed mango and mango industry}

\subsubsection{Mango varieties in Ghana}

The total Ghanaian mango production is about 99,000 metric tons in 2014. Most, about 80 to 95 $\%$ of these mangoes are Keith varieties [12]. The other commercial varieties cultivated in Ghana are Kent (about 10\%). Other minor varieties grown in Ghana includes Palmer, Haden, Erwin and Tommy Atkins. Keith mangoes are the predominant commercial mango variety cultivated in Ghana. One of the main characteristics of the Keith variety is that they have a long mature green ripe period, which makes the Keith colour misleading as a way to determine ripeness. In turn, this makes it difficult to sort Keith mangoes according to ripeness, an important characteristic that determines post-harvest handling and fresh market readiness. Nevertheless, the organoleptic characteristics of Keith mangoes are considered superior. Keith mangoes are described as fibrefree and their pulp are characterized as melting. They have thin seeds with an orange-yellow pulp colour. The smooth texture of the Keith mangoes together with their tangy sweet flavour lends to their superior eating and processing characteristics. Table 1 shows the physico-chemical properties of the various mango varieties cultivated in Ghana (as adapted from [13]).

\begin{tabular}{|c|c|c|c|c|c|c|c|c|c|c|c|}
\hline Variety & & \multicolumn{10}{|c|}{ Parameter } \\
\hline \multirow{3}{*}{ Haden } & Time & $\begin{array}{c}\text { TA (\% } \\
\text { citric acid) }\end{array}$ & $\begin{array}{c}\text { Ascorbic Acid } \\
(\mathrm{mg} / \mathbf{1 0 0 \mathrm { g }})\end{array}$ & $\begin{array}{c}\text { TSS } \\
\text { ('Brix) }\end{array}$ & $\mathrm{pH}$ & $\begin{array}{c}\text { Moisture } \\
(\%)\end{array}$ & DM (\%) & $\begin{array}{c}\text { Fibre } \\
\text { Content } \\
(\%)\end{array}$ & $\begin{array}{l}\text { Colour of } \\
\text { Pulp/nesh }\end{array}$ & $\begin{array}{l}\text { Consistency of } \\
\text { pulp/nlesh }\end{array}$ & $\begin{array}{l}\text { TSS/Acidity } \\
\text { ratio }\end{array}$ \\
\hline & $\begin{array}{l}\text { Initial Analysis at harvest } \\
\text { (Physiologically Mature) }\end{array}$ & 1.07 & 24.74 & 8.9 & 3.25 & 83.55 & 16.45 & 0.017 & turning yellow & $\begin{array}{l}\text { uniform consistent } \\
\text { texture }\end{array}$ & 8.32 \\
\hline & $\begin{array}{l}\text { Final Analysis when ripe } \\
\text { (eating soft stage) }\end{array}$ & 0.14 & 8.05 & 18.5 & 5.11 & 80.85 & 19.15 & 0.065 & deep yellow & $\begin{array}{l}\text { uniform consistent } \\
\text { texture }\end{array}$ & 132.14 \\
\hline \multirow{3}{*}{ Kent } & & $\begin{array}{c}\text { TA }(\% \\
\text { citric acid) }\end{array}$ & $\begin{array}{c}\text { Ascorbic Acid } \\
(\mathrm{mg} / 100 \mathrm{~g})\end{array}$ & $\begin{array}{c}\text { TSS } \\
\text { ('Brix) }\end{array}$ & $\mathrm{pH}$ & $\begin{array}{c}\text { Moisture } \\
(\%)\end{array}$ & DM (\%) & $\begin{array}{c}\text { Fibre } \\
\text { Content (\%) }\end{array}$ & $\begin{array}{c}\text { Colour of } \\
\text { Pulp }\end{array}$ & Consistency of pulp & $\begin{array}{l}\text { TSS/Acidity } \\
\text { ratio }\end{array}$ \\
\hline & $\begin{array}{l}\text { Initial Analysis at harvest } \\
\text { (Physiologically Mature) }\end{array}$ & 0.81 & 8.51 & 6.9 & 3.42 & 82.28 & 17.72 & 0.016 & turning yellow & $\begin{array}{l}\text { uniform consistent } \\
\text { texture }\end{array}$ & 8.52 \\
\hline & $\begin{array}{l}\text { Final Analysis when ripe } \\
\text { (eating soft stage) }\end{array}$ & 0.12 & 3.32 & 17.5 & 4.08 & 80.94 & 19.06 & 0.062 & $\begin{array}{l}\text { deep yellow to } \\
\text { orange yellow }\end{array}$ & $\begin{array}{l}\text { uniform consistent } \\
\text { texture }\end{array}$ & 145.83 \\
\hline \multirow{3}{*}{ Palmer } & & $\begin{array}{c}\text { TA }(\% \\
\text { citric acid) }\end{array}$ & $\begin{array}{c}\text { Ascorbic Acid } \\
(\mathrm{mg} / 100 \mathrm{~g})\end{array}$ & $\begin{array}{c}\text { TSS } \\
\text { ('Brix) }\end{array}$ & $\mathrm{pH}$ & $\begin{array}{c}\text { Moisture } \\
(\%)\end{array}$ & DM (\%) & $\begin{array}{c}\text { Fibre } \\
\text { Content (\%) }\end{array}$ & $\begin{array}{c}\text { Colour of } \\
\text { Pulp }\end{array}$ & Consistency of pulp & $\begin{array}{l}\text { TSS/Acidity } \\
\text { ratio }\end{array}$ \\
\hline & $\begin{array}{l}\text { Initial Analysis at harvest } \\
\text { (Physiologically Mature) }\end{array}$ & 0.93 & 35.47 & 7.3 & 3.33 & 83.89 & 16.11 & 0.017 & turning yellow & $\begin{array}{l}\text { uniform consistent } \\
\text { texture }\end{array}$ & 7.85 \\
\hline & $\begin{array}{l}\text { Final Analysis when ripe } \\
\text { (eating soft stage) }\end{array}$ & 0.31 & 5.52 & 19.1 & 5.00 & 80.25 & 19.75 & 0.066 & orange-yellow & $\begin{array}{l}\text { uniform consistent } \\
\text { texture }\end{array}$ & 61.61 \\
\hline \multirow{3}{*}{ Keitt } & & $\begin{array}{c}\text { TA }(\% \\
\text { citric acid) }\end{array}$ & $\begin{array}{c}\text { Ascorbic Acid } \\
(\mathrm{mg} / 100 \mathrm{~g})\end{array}$ & $\begin{array}{l}\text { TSS } \\
\text { ('Brix) }\end{array}$ & $\mathrm{pH}$ & $\begin{array}{c}\text { Moisture } \\
(\%)\end{array}$ & DM (\%) & $\begin{array}{c}\text { Fibre } \\
\text { Content }(\%)\end{array}$ & $\begin{array}{c}\text { Colour of } \\
\text { Pulp }\end{array}$ & Consistency of pulp & $\begin{array}{l}\text { TSS/Acidity } \\
\text { ratio }\end{array}$ \\
\hline & $\begin{array}{l}\text { Initial Analysis at harvest } \\
\text { (Physiologically Mature) }\end{array}$ & 1.04 & 23.80 & 6.6 & 3.35 & 84.26 & 15.74 & 0.026 & turning yellow & $\begin{array}{l}\text { uniform consistent } \\
\text { texture }\end{array}$ & 6.35 \\
\hline & $\begin{array}{l}\text { Final Analysis when ripe } \\
\text { (eating soft stage) }\end{array}$ & 0.10 & 3.66 & 17.0 & 5.80 & 81.95 & 18.05 & 0.094 & lemon yellow & $\begin{array}{l}\text { uniform consistent } \\
\text { texture }\end{array}$ & 170.00 \\
\hline
\end{tabular}

Table 4: Physico-chemical properties of mature ripe and eating stages of the various mango varieties grown in Ghana. ([13])

\subsubsection{Market for the Ghanaian mangoes}

Currently, the main market for the Ghanaian mangoes comprises the local fresh market. In 2014, about 47,000 metric tons of fresh mangoes were consumed by the local Ghanaian market [14]. In contrast, Ghanaian mango exports are quite low, amounting to only about 1 metric ton in the same year. This is a missed opportunity for the Ghanaian mango industry. One the other hand both domestic and export of Ghanaian processed mango products amounted to 20,000 and 13,000 metric tons, respectively in 2014. This suggests that there is already an established mango processing industry in Ghana. 
From a growers/farmers perspective, selling fresh mango for the fresh market is the most interesting from a sales price view. However, within the current supply in Ghana the collection and transport of mango is focussing mainly on physically moving the product 'from a to b'. Aspects like optimization of handling and package material, conditioning (temperature control), post-harvest treatment and using storage for time management is not yet the main focus. The current practice is not in favour for selling fresh mango. Also for processing, fresh mangoes are transported by road to processing facilities near Accra. At maximum, the fresh produce is loaded within one and a half day after harvest. After that, the produce is transported by road for maximum twenty-four hours. In addition, the transportation time of exported processed mangoes takes a lot of time. Products transported by road from Ghana to Burkina Faso can be easily delayed up to a week, due to formalities related to border crossing. Not only transport by road is difficult, but also by sea.

\subsubsection{Current state of mango processors in Ghana}

All levels of processing are currently at play within the Ghanaian mango processing industry. Small, medium and large-scale mango processors can be found along the main mango growing regions. Depending on the size of the company, operations may differ in terms of available postharvest facilities, product lines and market focus (domestic or export). However, in general the main mango products that the Ghanaian mango processors produce include mango juices, mango scoops and dried mango slices [15].

Small and medium scale mango processors rely heavily on agents and aggregators to source the mangoes they need for their operation. These intermediaries, so called market queens have direct links to independent mango growers and small/medium scale processors. On the other hand, there is no direct link between farmers and small/medium scale processors. For large-scale mango processors, mangoes are sourced either through growing contracts or through their own dedicated mango farms. This enables large-scale processors to have better control of mango quality and post-harvest operations.

\subsubsection{Large scale mango processing in Ghana}

In this paragraph, we address the large-scale processing industry in Ghana although it is outside the scope of the project. However, as part of the roadmap, it is good to place the small scale relative to the whole.

One of the main advantages of the large-scale mango processors is that most of them have their own dedicated mango growers. This enables them to plan production volume and shifts. In addition, the quality of fruits available for large scale processing is better since post-harvest facilities (such as cold storage rooms) are available for large-scale processors. The main products produced by large-scale processors in Ghana include mango juices and dried mangoes. While some large-scale processors already co-process other fruits such as pineapple and pawpaws to lengthen the production schedule, most of them still only operates for only three months in the 
year coinciding with the peak mango harvest season. This severely hampers productivity. As a result, a number of large-scale mango processors have closed down. In part due to the limited production schedule, but also due to high overhead for process inputs (energy, storage, and packaging, among others). Combined, these factors contribute to financial difficulties in maintaining a viable commercial large-scale mango processing plant in Ghana.

\subsubsection{Small/Micro level mango processing in Ghana}

Currently, small and micro level mango processing plants in Ghana produce mango drinks, fresh cut mangoes and dried mango slices for the local market. As with other mango processors, they use second and third grade mangoes for their operation. Due to the lack of transportation and storage facilities, they often have fruit quality challenges. This is more predominant during the peak mango harvest season when process capacity lags behind the supply of mangoes. Small and micro level mango processors in Ghana are very much reliant on intermediaries for sourcing the required mango for their operations. In many cases, processing shifts are dependent on the amount of mangoes that are available for processing. This is assessed on a daily or even per shift basis. However, excess mangoes in the major season is a huge challenge, which leads to high losses. A small/medium scale facility with a focus to process mangoes into intermediate products (puree, sliced and frozen fruits etc.) during the glut to extend the availability of processed mangoes in the off-season will have a much better chance of success.

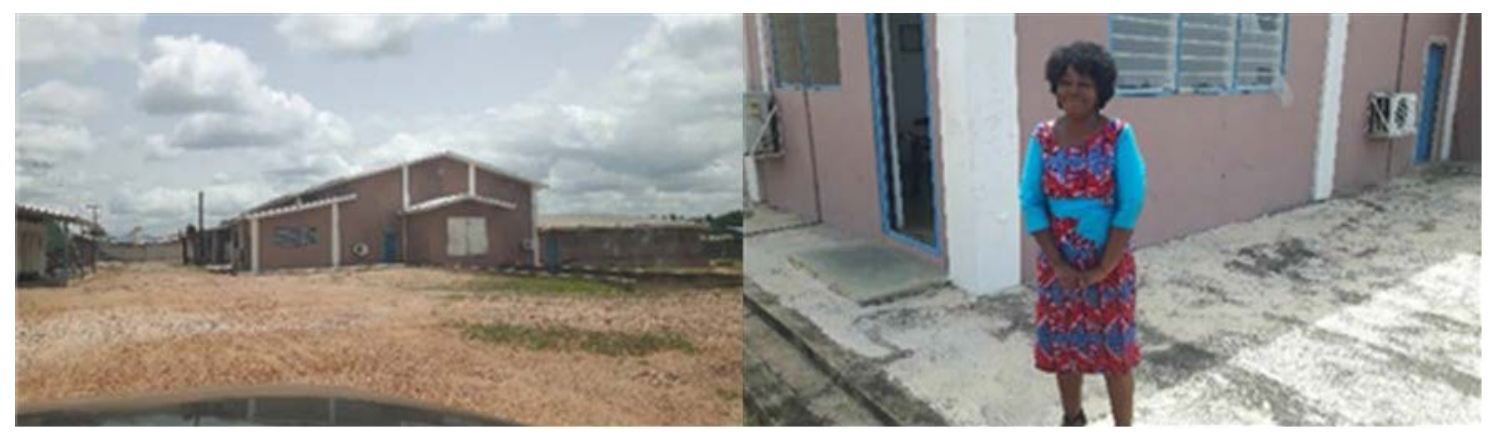

Figure 9: Mrs. Love Carr from Kokoby fruit processing, a medium scale mango processor near Accra (Photo: Jan Verschoor).

A Fresh Fruit Hub (FFH) in combination with a Small-scale Intermediate Processing Centres (SIPC) creates the opportunity to shift the focus from processed to fresh, and gives also the possibility to do some (low tech/small scale) processing near to the production fields allowing small scale farmers to take advantage of the best of the two worlds; getting a higher price by selling mango to the fresh market and add value through processing.

\subsection{Step 3: Mango supply chain challenges in relation to the ambition}

\subsubsection{General challenge: Black Spot Disease / Sufficient supply of mango}

In general, both the fresh mango market and mango processors report that the mango supply in Ghana does not sufficiently meet the required quality standards. This is attributed not only poor 
post-harvest handling, but also to pests and diseases that affect mango fruits. The analysis in phase 1 of this project and interviews with several stakeholders learned that the demand for mango is bigger than the current supply. The biggest challenge for the Ghanaian mango sector is that they presently suffer from the presence of Black Spot Disease (BSD). The BSD only worsens the shortage in supply and is a serious risk for the mango sector for being able to create a sufficient supply of mangoes.

Looking into new varieties could be a long-term approach. Now Keith and Kent are mainly produced. However, testing new varieties not only as a mean to eradicate BSD but also extend the production season is a desirable option. Currently large-scale producers already test other varieties. And also, the invitro development of plantlets that are resistant to the BSD by the Plant Genetic Resource Center of the Council for Scientific and Industrial Research (CSIR) will be in the medium to long term also a desirable development to overcome the BSD challenge.

Reduction of post-harvest losses, the main focus area within this project, will also have a direct positive contribution to the supply of mango.

\subsubsection{General challenge: Improve pre- and post- harvest practices and operation to minimize losses}

The Ghanaian fresh and processed mango industry cannot be developed independent of each other. In order to improve the mango processing industry, the fresh mango market must also be improved. Therefore, focusing on mitigating post-harvest losses by improving pre- and postharvest handling of fresh mangoes will be beneficial to both. First, the quality of mangoes for processing will be improved. Secondly, mitigating post-harvest losses will also mean more mangoes in the supply chain. This could potentially lower production and processing costs for mangoes directly or indirectly. In addition, the establishment of packinghouses at the farm and community levels will play an important first step in improving post-harvest handling. 


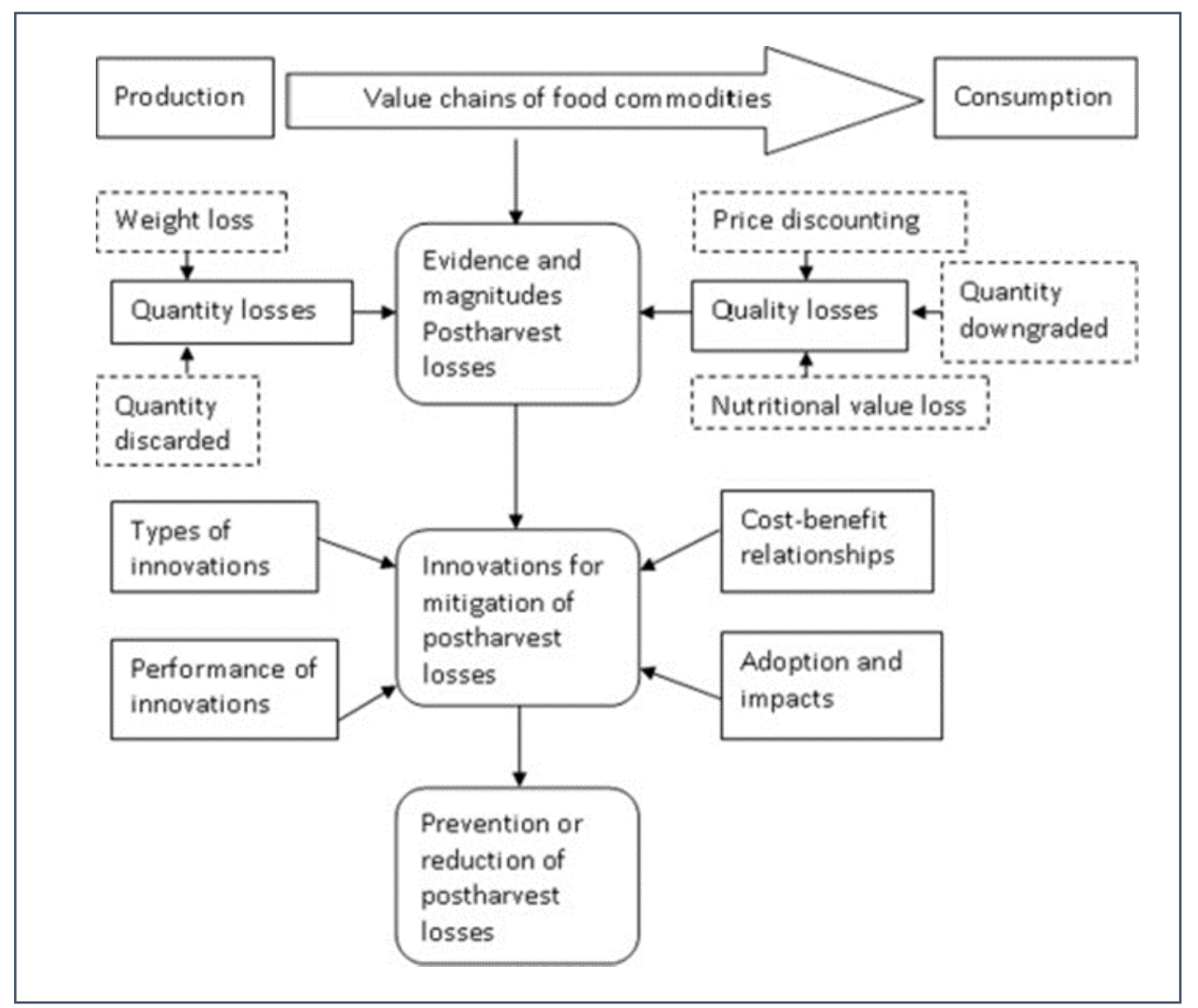

Figure 10: Conceptual framework on how post-harvest losses accrue and the dynamics of mitigation in Sub-Saharan Africa (adapted from [16])

The specific ambition and challenges discussed below should been seen in context of the above.

\subsubsection{Challenge: Setting up a small-scale Fresh Fruit Hub / Small-scale Intermediate Processing Centre}

Putting a new logistical and processing facility within a supply chain should achieve benefits for the whole chain, in other words have a systemic benefit with higher social and economic returns. Below a figure is presented (Figure 10) that summarises the main theory of scaling how a new logistical facility benefits the chain. The basic thinking is that establishing a FFH/SIPC strengthens the professionalization in the supply chain in the following way. Firstly, increased level of organisation and trained producers and staff of the centre allows for efficiencies at harvest and post-harvest level. The FFH/SIPC allows for increased product quality and quantity, which comply with minimum food safety standards.

Furthermore, the FFH/SIPC will help producers (cooperatives) meet food safety standards, and encourage them to apply new procedures and management. This step will require considerable training on handling the new equipment and complying with food safety procedures and standards. The FFH/SIPC can serve as a so-called base where the necessary trainings can be facilitated and thus will result in a significant improvement of the quality of fresh and processed 
fruits. In the end, conformity with food standards will enable Ghanaian producers to adopt stronger positions in their current markets and enter new markets.

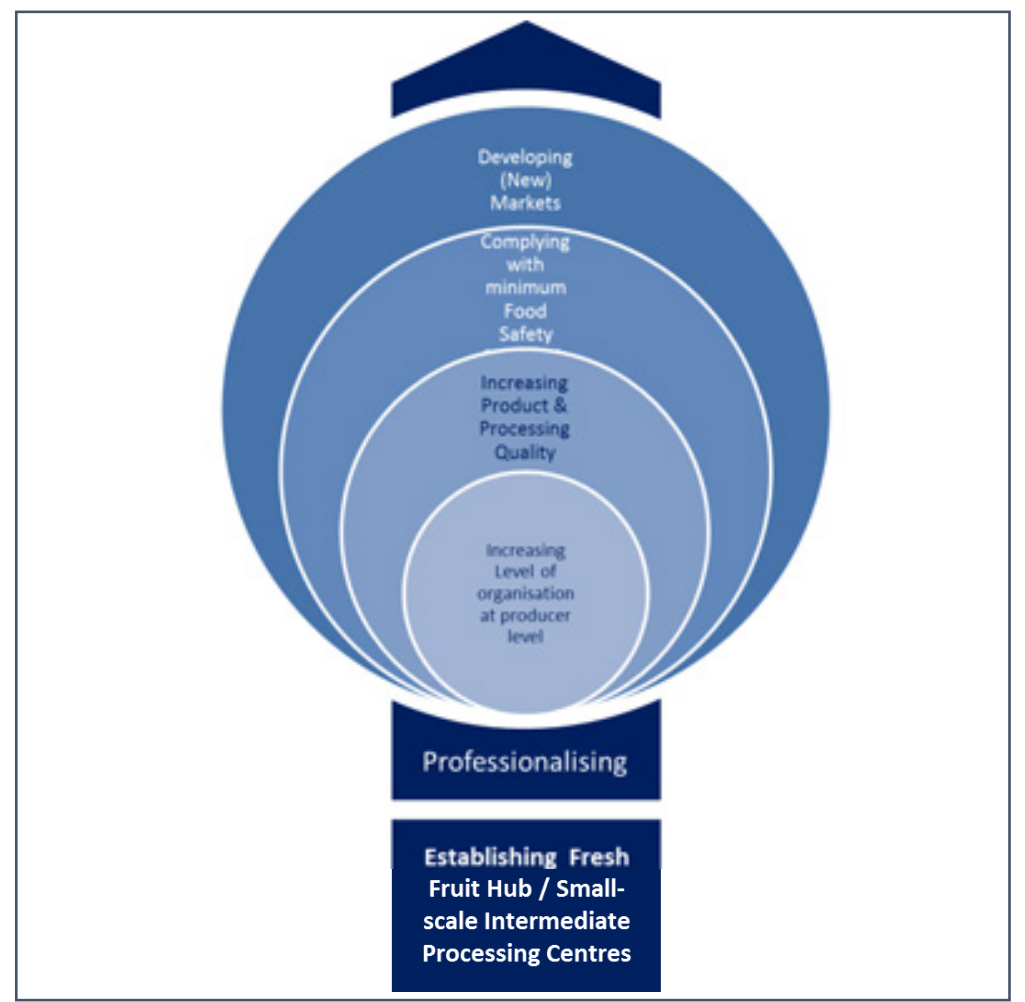

Figure 11: Visual summary of anticipated systemic changes created by the Fresh Fruit Hub / Smallscale Intermediate Processing Centres (Source: Wageningen Food \& Biobased Research)

\subsection{Step 4: Relation to roadmap structure: the mango roadmap}

The challenge for the mango supply chain is already reasonably defined based on the insights gained from the previous studies and workshops. This means that an emphatic focus has already been placed on certain elements described in the methodology. After all, the ambition is to realize a physical hub in the existing supply chain of mango. The starting point is that this hub will not only contribute to the possibility of shifting from processed mango to the market of fresh (unprocessed) mango, but also that this will contribute to the professionalization of entire mango value chain. Elements that have already been implicitly included in the formulation of the ambition, to a greater or lesser extent, are (see also Figure 3):

- Physical/geographical:

- Infrastructure

- Facility layout/technology level

○ Location stock points 
- Control:

O Organize information flow

- Information

○ Market information, mainly supply

- Organization

○ Coordination of task

- Finance

- Financial resources, aimed at realizing the FFH/SIPC

- Knowledge/skills

○ Skilled labour

○ Production knowledge

In relation to the formulated ambition, the following elements are explicit:

\begin{tabular}{|lll|}
\hline Physical/geographical: & Facility layout/technology level & $=\mathbf{1}$. Functionality \\
Physical/geographical: & Location stock points & $=$ 2. Location \\
Organization: & Coordination of task & $=\mathbf{3}$. Ownership \\
Finance: & Financial resources, aimed at realizing the FFH/SIPC & $=\mathbf{4}$. Investment \\
\hline
\end{tabular}

\subsection{Step 5: The current $\&$ target situation}

In this section, steps 5 and 6 are taken together because the ambition to set up the Fresh Fruit Hub in the mango supply chain is based on the assumption that the possibilities offered by such a facility are currently not, or at least insufficiently, present in Ghana (see phase 1 of this project)

To achieve a clear, worn and well thought-out formulation and description of a FFH/SIPC relevant for the Ghanaian situation it is needed to take the above mentioned elements as a guidance for the Ghanaian government (Ministry of Trade \& Industry, Ministry of Food \& Agriculture), whether in cooperation with the World Bank, NGO's, CBO's, et cetera.

\subsubsection{Determine the main functionalities of the Fresh Fruit Hub / Small-scale Intermediate Processing Centre}

Before determining the functionalities of the FFH/SIPC, it is essential to describe the type of products to be serviced in the FFH/SIPC. There are two production seasons for mango in Ghana, but these seasons are short. Mangoes can be harvested for 2-3 months. Building a facility or hub only for mango would mean that these facilities would be idle in the off-season period. Most logic is to use the facilities for other products, preferably in the counter-season from mango. Other fruits like pineapple and oranges can be sourced to keep the facilities from being idle. Pineapple is grown in the South, and oranges are produced in the Central region of Ghana. Both production areas are in relative near distance to Ashanti and Brong-Ahafo and could thus be interesting complimentary products. 
The choice of product also has an impact on the activities or functionalities of the hub. For example, when cooling is a major service that is planned in the hub then bananas are probably less interesting because they do not need cooling and thus will not 'fill' the cooling facilities.

Because of the short harvest season of mango target the

$\mathrm{FFH} / \mathrm{SIPC}$ for multiple products, preferably pineaple, oranges, ...

\section{The functionalities of the FFH/SIPC}

Description of functionality i.e. the range of operations or services that can be run by the FFH/SIPC:

- Issuance \& Storage of harvest/collection packaging:

- This means providing harvest package as a service for connected growers and grower associations. This function leads to investments in package, area to store these packages and a cleaning area to clean the package (packaging for multiple use). The packages should be designed to service several products when the hub is focussing on more than just mango as suggested in step 1.1 (size, strength, material, technical design). The package material should be adapted to local transport methods and in future expected systems. At the hub, the movement of the package material could be done by hand.

- Goods Receipt \& entry control:

○ Cleaning area of harvest/collection package (this includes sampling and check for fruit fly);

- Product quality control;

- Washing or other product specific treatment. For example heat treatment in case of mango;

- Administration: weighting of product, counting product, registration of quality;

- In addition, some initial certification from the Green Label Certification Program of Ghana can take place at this stage.

- (Cold) Storage: a small cold storage room can be used to buffer product before further handling. For local selling this cold room can also be used as small stock. (= buffer product in): In case the production capacity of the facility is not sufficient according to the product supply, a (cold) storage is needed to buffer the product. 


\section{- Prepare for shipping (Fresh product)}

○ Sorting;

- Packing (domestic market and export): In the centre, some basic quality sorting can be done. In case of export, washing and drying can be applied. After that the preparation for the packing line can be done. This includes careful dumping of the crates with fruit on a packing line conveyor belt, grading of the fruit, waxing of the fruit, sizing of the fruit, carton filling and dispatch removed fruit. The type of the boxes, the sizes, and the construction will be specific for the market and based on small volumes. In a temperature controlled chain the requirements of the cartons are specific (resistance to moisture);

- Assembly of package: At the hub, in general some basic packing material for outgoing product will be used. When the final packing is done at the hub, some exchange system for package material is possible. In Europe a system with Euro Pool is used, where at several positions the package material can be hired or returned;

- Cold storage: Next to temperature storage conditions like $\mathrm{CO}_{2}$, level of ethylene (natural ripening hormone), tolerance to specific volatiles, could also be relevant. The storage facility can be used for buffering (market speculation), servicing for retailers or for closing the cold chain. Depending on the product the applied storage condition should be optimized but in case of handling several product the final condition will be suboptimal for some (not 'one size fits all');

○ Staging out.

\section{- Information on transportation}

- The hub can organize as a service transport between production field and hub facilities. Intense communications between suppliers and the management of the hub is most important to minimize time between moment of harvest and entrance of the hub. Organizing contains at least the availability of transport vehicles (owned or organized), communication (transport planning) and strict instruction/protocols in best practices (this includes loading and unloading of the truck, transport and temperature measurement of the fruit).

- In addition, basic data (information) on production source will enhance traceability for both processed and fresh produce. 
The FFH/SIPC should incorperate the basic functionalities with the start a focus on:

- Providing harvest package \& packaging for

domestic market

- Goods receipt \& entry control

- Small cold storage room, preferably 'off grid'

- Transport planning \& protocol development

\section{- Processing \& training:}

Below more detail is given related to two functionalities; processing and training (office). The main power of the hub is that products (both volume and different types), activities, functionalities and people are brought together. Beside the above-mentioned functionalities, this gives the opportunity not only to handle the fresh mango but also to process mangoes and even more interesting, training people. Because of the somewhat different character and the broader scope of these functionalities, they are explained separately.

\subsubsection{Functionality FFH/SIPC: Processing}

Currently, the main market for fresh Ghanaian mangoes remains the local Ghanaian market. However, the post-harvest losses in the local fresh mango industry signal an opportunity for processing mangoes into other value added products. The excess mangoes in the major season is a huge challenge, which leads to these high losses. A small/medium scale facility with a focus to process mangoes into intermediate products (puree, sliced and frozen fruits etc.) during the glut to extend the availability of processed mangoes in the off-season has a chance of success. The demand for processed mangoes is high. Currently large-scale processing facilities already purchase processed products, and they favour these processed mangoes, since the volumes for transportation are lower than for fresh produce. Processing mangoes into juice adds the highest value to the product. However, for example in the Kokoby fruit processor, the mango is first process into puree and this puree is then processed into juices. This gives opportunities for smallscale processing facilities, since processing into puree or pop can be relatively low tech. For processing pop, it is possible to process locally. This can be at two ways. With a mobile processing unit or local small-scale cottage processing. Therefore, the main activity is to set up a small-scale processing facility near the production fields.

For the FFH/SIPC this could lead to

I. Improvement of post-harvest operations

a. Increase quality of fresh mangoes for fresh market

b. Sort processing mangoes appropriate

II. Value added processed mangoes for domestic market

a. Mango puree (nectar and juices, sauces) 
b. Dried mango (sun dried) (note: is hardly applied in Ghana and may therefore be a new market opportunity to be developed and needs market research)

c. Mango pickled / relish

d. Mango diced/scoops

I. Focus on two main processed mango products for large scale export market:

a. Mango puree and dried mangoes

i.Both minimal process inputs required

ii.Streamlined processing, easier certification

II. Improve production schedule for small- and medium sized mango processors

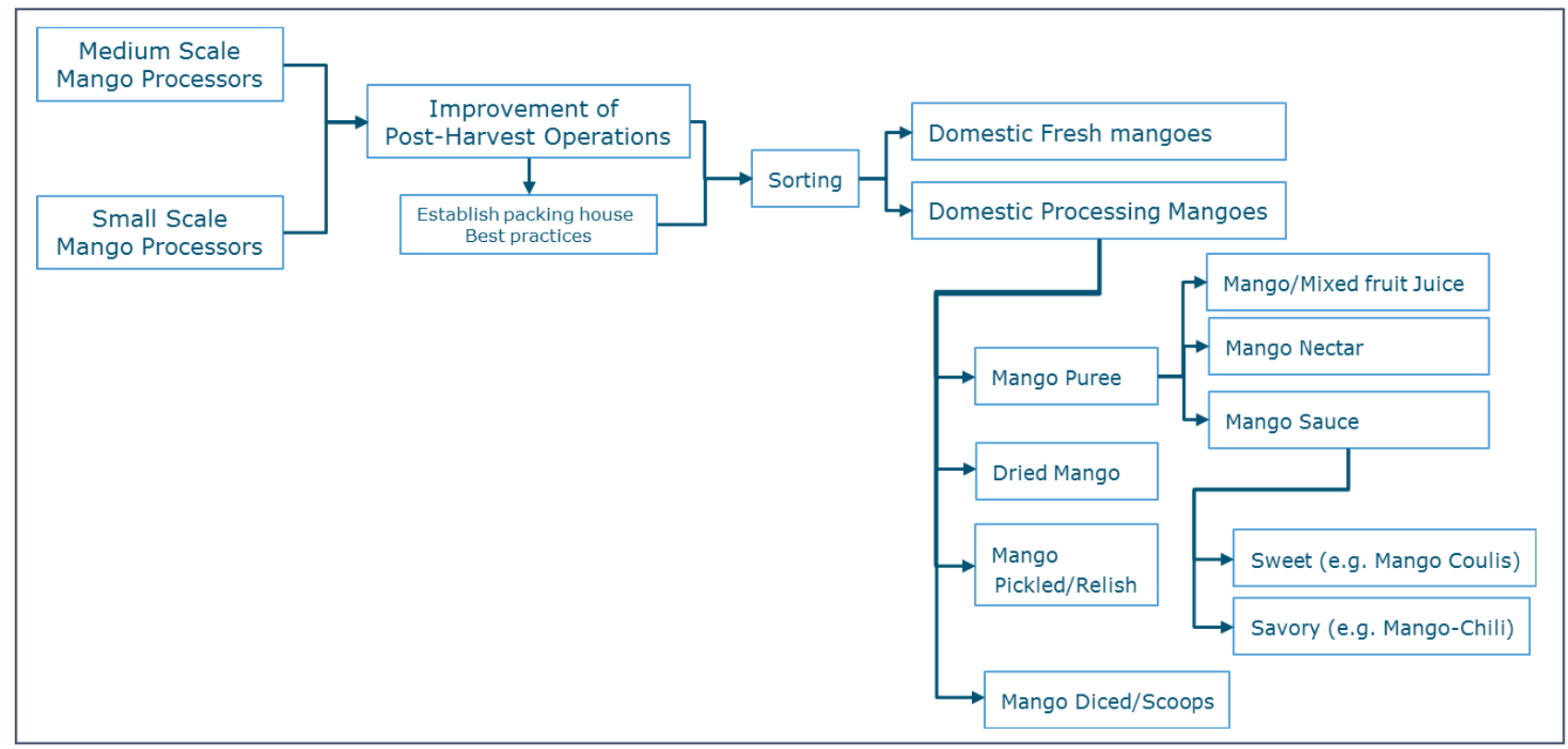

Figure 12: Medium \& small-scale mango processors roadmap (Source: Wageningen Food \& Biobased Research)

Currently processors only process during high season, because the quantities are high and the prices low. At the beginning and ending of the growing season processors process on average three times less product than during the peak season.

- Depending on the products handled in the hub, the required technology must be described. In general, food processing requires a high level of hygiene. The area of processing will be controlled in temperature adapted to presence of people and product specific demands (e.g. avoiding condense inside the package). Examples of expected processing technology of the handled products are:

- cutting and consumers convenience packaging of leaf product and fruits;

- drying of fruits;

- juice production;

- production of marmalades/jams. 
When taken processing as a service (i.e. domestic processing, small \& medium scale) into account a production schedule could be established for processing mango and other fruits:

- mango (April-June, minor season December-February);

- pineapple (October-December, minor season February-April);

- orange (mostly year round)

- banana (mostly year round)

- other exotic fruits (mixed fruit juices can be made)

An example of a year round plant production schedule should coincide with major harvest seasons of major commercial fruits in Ghana.

\begin{tabular}{|c|c|c|c|c|c|c|c|}
\hline \multirow{2}{*}{$\begin{array}{l}\text { Calendar } \\
\text { month }\end{array}$} & \multicolumn{4}{|c|}{ Harvest Season } & \multicolumn{3}{|c|}{ Process Schedule } \\
\hline & mango & pineapple & orange & banana & mango & pineapple & mixed juices \\
\hline January & & \multirow{4}{*}{ season (minor) } & \multirow{12}{*}{$\begin{array}{c}\text { mostly year } \\
\text { round }\end{array}$} & \multirow{12}{*}{$\begin{array}{l}\text { mostly year } \\
\text { round }\end{array}$} & & & \multirow{3}{*}{$\begin{array}{c}\text { mango-pineapple } \\
\text { mango-banana, } \\
\text { mango-orange }\end{array}$} \\
\hline February & & & & & & & \\
\hline March & & & & & & & \\
\hline April & \multirow{3}{*}{ main Season } & & & & \multirow{3}{*}{$\begin{array}{l}\text { purees, } \\
\text { scoops, dried } \\
\text { mangoes }\end{array}$} & & \\
\hline May & & & & & & & \\
\hline June & & & & & & & \\
\hline July & & & & & \multirow{3}{*}{$\begin{array}{l}\text { nectars, juice, } \\
\text { sauces, mixed } \\
\text { juices }\end{array}$} & & \\
\hline August & & & & & & & \\
\hline September & & & & & & & \\
\hline October & & \multirow{3}{*}{ main season } & & & & \multirow{3}{*}{$\begin{array}{l}\text { juices, } \\
\text { rings, } \\
\text { spears, } \\
\text { crushed }\end{array}$} & \\
\hline November & & & & & & & \\
\hline December & season (minor) & & & & & & \\
\hline
\end{tabular}

Table 5: Example year round plant production schedule (Source: Wageningen Food \& Biobased Research)

Note:

- Co-processing of pineapple and mangoes are complimentary

- Main products for processed mangoes during peak harvest: puree and dried mangoes

- Processing nectars and juices from mango (in off season)

- Also processing value added products in off season has benefits 
- Equip the FFH/SIPC with a mobile processing or local smallscale cottage processing unit

- Value added processing for the domestic market and focus on two products for export (puree and dried)

- Established for processing mango and other fruits (pineapple, oranges, banana, ...) production schedule

\subsubsection{Functionality FFH/SIPC: Training (office) = Improving harvest and first handling practices on-farm}

All companies and persons involved, including growers, traders, packers, transporters, and exporters, need to understand the impact of their handling on the quality of the perishables. Many growers do not recognize their product after some days of chain transfer. Initiatives in training and education of growers are essential. Next to technical improvements to introduce a closed cold chain, appropriate training is important in improving product quality and reducing food losses.

Today, agricultural extension approaches in Ghana range from the top-down commodity-based approaches to more participatory approaches like the World Bank's Training and Visit (T\&V), commodity participatory approaches, the farmer field schools (FFSs), the innovative ICT based approaches which provide advice to farmers on-line, and the promotion of mobile phones and community radio stations. These approaches have been promoted over the years by the various extension service providers, including government (MoFA, the main actors in extension like the Directorate of Agricultural Extension Services (DAES) (http://mofa.gov.gh/site/?page id=74). In addition, they host the official website of private agricultural extension / advisory service providers (http://www.privateextensionghana.com), non-governmental organizations (NGOs), producer organizations and other farmer organizations ${ }^{6}$.

Basically, there is a knowledge infrastructure, organisational embedding, et cetera present in Ghana. Therefore putting a completely new post-harvest management learning system into place is not part of this roadmap. Moreover, the Fresh Fruit Hub could serve as a logical cluster point where different stakeholders from the mango chain come together for different training activities.

The first phase of this project [1] learned that in respect to the mango supply chain mainly harvest and first handling practices on-farm should be improved. The focus of the training by the existing organisations could focus on these aspects. The extension service providers could also develop in close cooperation with the owner of the FFH/SIPC and the affiliated farmers/ producer's post-harvest handling and small-scale processing protocols for management, hub employees farmers, et cetera. These protocols should be easy and practical.

${ }^{6}$ http:// wmw.g-fras.org/en/world-wide-extension-study/ africa/western-africa/ghana.btml (seen 2018-06-25) 
- Esthablisch the FFH/SIPC as a logical cluster point to facilitate training and education to increase accessibility

- Focus training, in close cooperation with the existing extension service providers (both governmental and (semi-) private), on harvest and first handling practices on-farm

\subsubsection{Location of the FFH/SIPC}

Many (construction related) issues are conditional for being able to build a facility such as a FFH/SIPC for example the presence and accessibility of infrastructure (mainly roads), presence of energy/accessibility to the energy grid, availability of building ground, ... These constraints and requirements are relevant, but out of scope of this project and therefore not further elaborated upon.

The location of a FFH/SIPC also strongly depends on the total chain design and the time of movement of products in and between different chain steps. Often special product storage and processing technology is expensive, so only in case of sufficient product volume, these technologies will be economically interesting. For example, the most important activity to start small-scale processing is to aggregate a group of farmers to process the fresh produce. A distance of 20 kilometres seems feasible to aggregate producers around one processing facility. Mango associations are organised well in Ghana what make aggregation easier. From here, the processed product should be picked up as well. Therefore, the location of this facility is important. The facility will be best located near the production area on the main market roads, paths or trails in the communal subsections.

Furthermore, the FFH/SIPC needs to be assessed as part of a regional or national network of facilities designed to reduce loss and increase efficiency of fresh products supplies for both export and domestic markets.

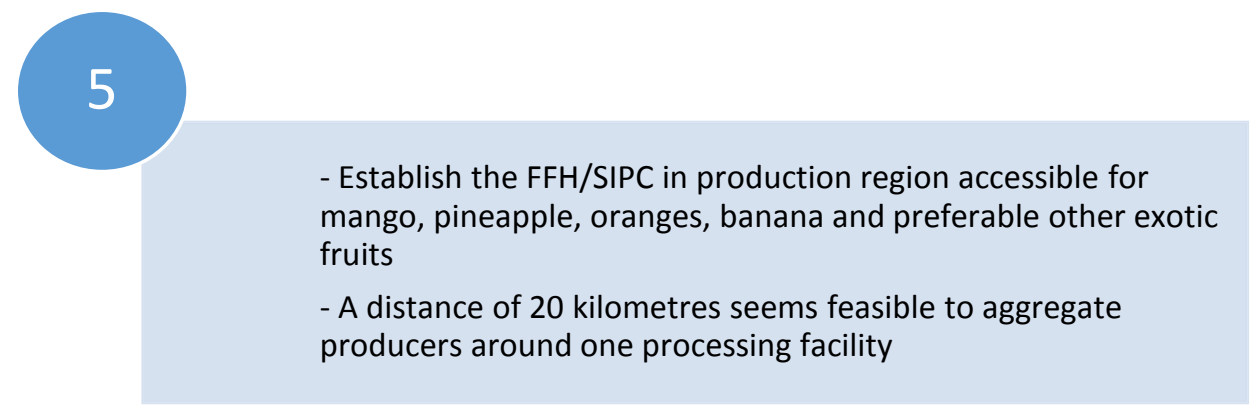




\subsubsection{Ownership of the FFH/SIPC}

Ownership of the hub is an important issue for success. Ownership can be organized in different ways. For example, cooperatives of the grower associations or larger growers or traders can be owner. In addition, a commercial service provider can operate the hub as well, in a position free of production or trading. Of course, the ownership of the hub can also be part of a (group of) cooperative(s). For strengthening of the position of the growers, a connection between the growers/growers organisation and the ownership of the hub must be strong. For the FFH/SIPC, a public private partnership (PPP) design seems appropriate to leverage additional resources by combining public and private investments with functions like control of food standards, fresh products service hub and vocational training. Such a PPP can be rolled out especially under the Ghanaian government's current programme of setting up Special Economic Zones.

Based on the type of ownership the involvement and influence of growers/farmers will be different. However, a hub will need a certain guaranteed volume to be able to operate optimally. Contracting and registration of participating farmers is essential. An analysis of the general planning of locations and yields is needed. Depending on the type of ownership and the management of the hub growers will participate in discussions related to planning and organization of services in order to have a voice on decisions related to type of products to be processed at the collection centres, cost of services et cetera.

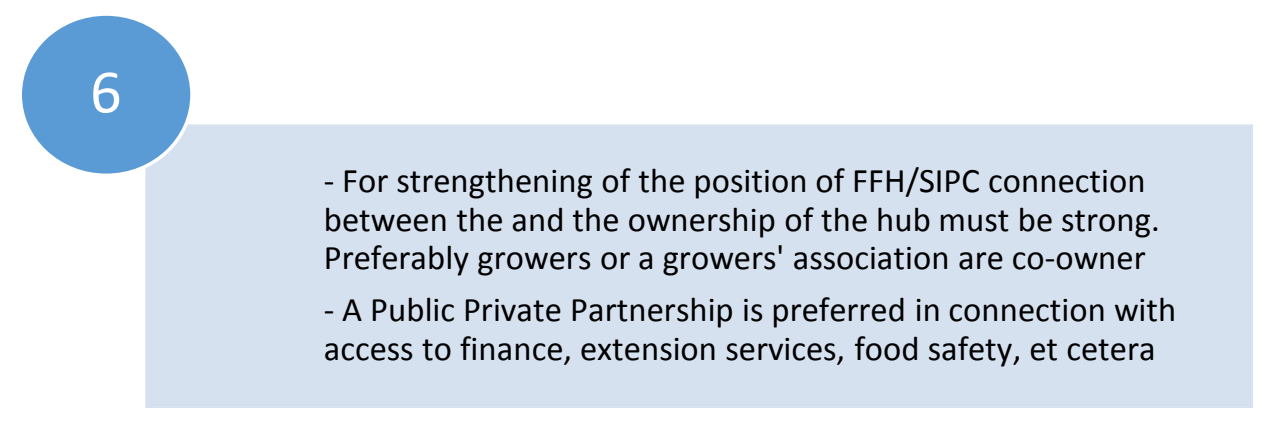

\section{Operational management of the FFH/SIPC}

The management of the centre and assuring adequate human resources is important. Registration and contracting of participating farmers need to be done. A number of management preconditions will have to be assured by the operating team, including the following elements:

- presence of protocols and application of these

- maintenance program of technology

- organisation of water and energy supply

- development of knowledge in procedures handling fresh products

- development of quality checks 
- Good (operational) management and management structure is crucial

- Training of potentiel personel has to be priority before developing the FFH/SIPC

- Have a neutral but engaged player with a commercial background as the service provider to manage the FFH/SIPC

\subsubsection{Investment related to the FFH/SIPC}

\section{Determine the size of the hub}

This is for a greater part depending on the product volume to be 'handled'. The range of product volume that practically can be handled at the location will be strongly depending on the final chosen products, the activities (packing, conditioning, ripening), the level of organisation and the market situation. Also, consider future expansion.

\section{Determine type of equipment and technology}

Determining the type of equipment that is needed based on the functionalities, products, volumes, et cetera.

\section{Determine building structure}

The building structure includes preparation of the soil, fencing, foundation, sewerage, floor, external walls, roof, doors and windows, and internal walls. Materials should be selected based on the technology present in Ghana.

\section{Determine labour cost}

Because of the importance of costs of labour in the operation of a hub, an estimation of functions are needed. The following functions could be necessary:

- Operational director/financial director

- HR management

- Floor managers

- Logistic/planner in- and external

- Technical engineer

- Receptionist / procurement

- Operational packaging employers

- Logistic employers

- Cleaning

- Messenger, security

- Driver 


\section{Determine operational cost}

The operation in the hub will strongly depend on the product flow during the production season of the chosen products to be 'handled'. As rule of thumb the occupancy rate should be maximized (> $60 \%$ ) for the perishables selected, but the facility can be used for other operations that can benefit of the (cooling) technology as well to increase the occupancy (for example the storage of medicines). In case of other operations, these should not interfere with the planned operation. This is a managerial decision.

Type of operational cost to take into account:

- redemption of investment of building

- redemption of investment of technology/equipment

- energy, especially related to the cooling equipment. To be noted that the supply of energy is a challenge in Ghana. Energy is expensive and not reliable.

○ cost for operating a diesel generator

- maintenance

- labour costs (management, operational people)

- the operational cost also has to include (not exhaustively):

$\circ$ interest

- costs of property of the building zone

- operational protocols

○ administration system

○ planning and administration system

○ track and trace system

$\circ$ package material

\section{8}

- Join expertise and knowledge from the Ghanaian governement, growers' associations, traders' associations, private sector and NGO's to get a well-substantiated idea regarding the necessary investments

- Create synergies with existing projects and build on their experiences and maybe financing

\subsection{Step 6: Activities and resources}

The Fresh Fruit Hub/Small-scale Intermediate Processing Centre will help boost production and quality and thus will result in systemic changes, as illustrated in Figure 10. Setting food safety standards will help raise the professionalism of producer cooperatives by guiding training and encouraging improvements in procedures and management. These enhancements will boost the quality of processed fruits, improve farmers' positions in the export and domestic markets, 
facilitate entrance into new markets, and, in turn, increase incentives for compliance with standards.

The approach described above will lead to a clear, worn and well thought-out formulation and description of a FFH/SIPC. Therefore will be a well-defined starting point and stepping stone towards the actual realisation of this so-called FFH/SIPC. Next steps would be (note: these activities have not been further worked out because this is outside the scope of the roadmap):

A. Committed and formalized ownership, management and human resources for the centre to make sure that continuation of the processing facility is guaranteed;

B. Aggregate farmers who all have the same ambition in starting up and to invest in a small-scale processing facility near the production field;

C. Formulating a business plan and finding funding/investors;

D. Functional description and design of the hub, procurement process and construction;

E. Education and training of employees' facility. Employees working at the facility should be trained in sorting, washing, etc. to have a high productivity.

F. Education and training of farmers: Farmers obtain more knowledge to optimize growing conditions and on post-harvest handling to receive better results and less food loss.

\subsection{Concluding remarks mango roadmap}

The improvement of mango quality from the Ghanaian mango industry should take priority. Mainly because many of the challenges that both the fresh and processed mango industry in Ghana face are quality related. Production difficulties, post-harvest losses, fruit standard problems, among others are all unified by an underlying need for improved quality. There are both a short term and a long-term view in improving Ghanaian mango fruit quality.

In the short term, the establishment of FFH/SIPC to help with post-harvest handling of small and independent mango farmers will have an immediate impact on the quality of mango fruits for the fresh and processed industries. These hubs will serve as the first post-harvest processing centres for newly harvested mangoes. Since ripeness of Keith, variety is difficult to determine through colour, specific density could be a practical way of determining ripeness. Therefore, within FFH/SIPC washing, sorting and cooling operations for mangoes just after harvest can be done centrally and uniformly.

Aside from establishing these hubs, improving of cultivation practices for mangoes will also affect the overall mango quality. Instituting best practices such as top pruning to minimize pest and disease problems while promoting flowering, flower induction procedures to have an offseason mango harvest, sustainable ways to control pests and overall orchard hygiene will provide the needed agronomic changes for the Ghanaian mango industry to improve fruit quality. This is more important now while the Ghanaian government is promoting mango cultivation. Alongside this promotion program should also be the training for best practices in mango cultivation. 


\section{Conclusion and remark}

In this report a methodology for designing a roadmap was developed. The methodology was applied for both the tomato and the mango supply chain/(processing) sector in Ghana. The developed and presented methodology can be applied independently. However, it should be noted that in order to apply the roadmap methodology prerequisite research needs to be carried out with respect to product-market combinations and regional preferences. The decision on what product(s) and what region(s) are selected has been made in earlier stages, like in this project. These results must be taken as a starting point for the roadmap.

The activities for both tomato and mango cannot be seen separately. Only if the complete list of actions is considered the roadmap will contribute structurally to the ambitions and the total vision. The best way forward according to the authors is to tackle the oversupply by various kinds of processing. Start small scale mainly for the local markets and try to achieve stability in income, continuity in flow of a certain variety and quality and hence gain trust from the farmers. Select farmers that are willing to cooperate, set up a project team with members from a local tomato association and a representative from the government. Build a network of researchers to ask for input, advice, or short-term involvement and grow from there.

Furthermore, the methodology focuses on private sector leading enterprise development notwithstanding the fact that policy is a key determinant that can drive the development of enterprises. As addressed in the methodology to increase the chance of success whether it is the concept of the creation of logistics hubs, micro or macro level processing centres or supporting infrastructure, it should be linked with policy.

The final and important remark is that the road map also focuses on post-harvest management. It is assumed that production issues are solved, which currently is not the case in Ghana. For tomato as well as mango diseases hinder every kind of progress and are the main concern for farmers at the moment. The road map can only be applied when production is up and running again. 


\section{References}

1. Gustavsson, J.C., Christel ; Sonesson, Ulf ; van Otterdijk, Robert ; Meybeck, Alexandre ; Food and Agricultural Organisation of the United Nations,, Global food losses and food waste. 2011.

2. H. Charles J. Godfray, e.a., Food Security: The Challenge of Feeding 9 Billion People. 2010: p. 8.

3. IDRC, C., ICIPE, Postharvest losses in Africa: Analytical review and synthesis - Gaps and outlook for future postharvest research and innovation in sub-Saharan Africa. 2013: p. 90.

4. Vorst, J.v.d., Effective Food Supply Chains: Generating, modelling and evaluating supply chain scenarios. 2000: p. 329.

5. Porter, M.E., Competitive Advantage of Nations: Creating and Sustaining Superior Performance. 2011: p. 896.

6. Agyekum, E., Overview of Tomato Value Chain in Ghana. 2015: p. 35.

7. Robinson, E.J.Z. and S.L. Kolavalli, The Case of Tomato in Ghana: Processing. 2010: p. 14.

8. Baba, I.I.Y., J. Yirzagla, and M. Mawunya, The tomato industry in Ghana - Fundamental challenges, surmounting strategies and perspectives. A review. 2013: p. 6.

9. Monney, E., V.E. Poku, and E. Armah, Baseline survey of tomato production in Ghana: A study of twelve production districts in four regions. 2009.

10. Owureku-Asare, M., et al., Consumer knowledge, preference, and perceived quality of dried tomato products in Ghana. 2016: p. 8.

11. Adu-Gyamfi, R., Fearon, I. and Addo, B, Profitability of organic mango production in northern region of Ghana- Case study of Integrated Tamale Fruit Company (ITFC). 2012: p. 11.

12. Zakari, A.K., National Mango Study. 2012: p. 58.

13. M, A., Quality criteria for mango export in Ghana. PhD Thesis. 2010.

14. Melle, C.a.B., S., chapter 10: Comparative analysis of mango value chain models in Benin, Burkina Faso and Ghana. 2013: p. 32.

15. Komayire, D., An assessment of current status, future trends and opportunities for improving mango production in Ghana. 2017: p. 8.

16. H, A., et al., Unpacking post-harvest losses in sub-Saharan Africa: A meta-analysis. World Development 66: pp 49-68. 2015. 


\section{Appendix A Elements from the 2 models used}

In an overview is presented of the elements in both models. All of them are merged into 6 categories that are closely related to the ones in the models. The result is shown in. Note that in case of the Porter Diamond model already some elements are a little more specific for the horticultural sector. This way the integration to one set is more logical.

\begin{tabular}{|c|c|}
\hline Supply chain model & Porter Diamond model \\
\hline Physical design & Factor conditions \\
\hline Geographical position of stakeholders & Skilled labour \\
\hline Infrastructure (buildings, roads) & Land availability \\
\hline Roles to be performed by whom & Production knowledge \\
\hline Facility layout & Financial resources \\
\hline Location stock points & Natural circumstances \\
\hline \multicolumn{2}{|l|}{$\begin{array}{l}\text { Characteristics of the means, i.e. machines and } \\
\text { personnel, and products }\end{array}$} \\
\hline Control design & Related and support industries \\
\hline CODP & Seed supply \\
\hline Lead time & Other small-medium scale processors \\
\hline Organize information flows & Foreign investors \\
\hline Organize input flows & Microcredits \\
\hline Set up training & Technology level \\
\hline Information & Demand conditions \\
\hline Market information (supply, price) & Market size \\
\hline Analytical information (trends) & Market growth \\
\hline \multirow[t]{2}{*}{ Transaction information (status payment) } & Market preferences \\
\hline & Innovation (new products) \\
\hline Organization & Firm strategy, structure and rivalry \\
\hline Coordination of tasks & Competition within the region \\
\hline Linkages vertical and horizontal in supply chain & Level of organization \\
\hline \multirow[t]{9}{*}{ Decision making } & Fresh versus processed \\
\hline & Chance \\
\hline & Climatically variation \\
\hline & Political change/instability \\
\hline & Government \\
\hline & Infrastructure \\
\hline & Extension services \\
\hline & Subsidies / tax incentives \\
\hline & Policy \\
\hline
\end{tabular}

Table 6: List of all elements from the two models 


\begin{tabular}{|c|c|}
\hline Physical/geographical & Control \\
\hline $\begin{array}{l}\text { - Geographical position of stakeholders/land } \\
\text { availability/natural circumstances } \\
\text { - } \quad \text { Infrastructure (buildings, roads) } \\
\text { - } \text { Roles to be performed by whom/seed supply/other } \\
\text { - } \quad \text { Facility layout/technology level } \\
\text { - Location stock points } \\
\text { - } \quad \text { Characteristics of the means, i.e. machines and } \\
\text { personnel, and products/fresh vs processed }\end{array}$ & $\begin{array}{ll}\text { - } & \text { CODP } \\
\text { - } & \text { Lead time } \\
\text { - } & \text { Organize information flow } \\
\text { - } & \text { Organize input flows }\end{array}$ \\
\hline Information & Organization \\
\hline $\begin{array}{ll}\text { - } & \text { Market information (supply, price) } \\
\text { - } & \text { Analytical information (trends) } \\
\text { - } & \text { Transaction information (status payment) }\end{array}$ & $\begin{array}{ll}\text { - } & \text { Coordination of tasks } \\
\text { - } & \text { Linkages vertical and } \\
\text { - } & \text { horizontal in supply chain } \\
\text { - } & \text { Decision making }\end{array}$ \\
\hline Finance & Knowledge/skills \\
\hline $\begin{array}{ll}\text { - } & \text { Financial resources } \\
\text { - } & \text { Foreign investment } \\
\text { - } & \text { Microcredits } \\
\text { - } & \text { Subsidies/tax incentives }\end{array}$ & $\begin{array}{l}\text { - } \quad \text { Skilled labour } \\
\text { - } \quad \text { Production knowledge } \\
\text { - Extension services } \\
\text { - Set up training }\end{array}$ \\
\hline Market & External \\
\hline $\begin{array}{ll}\text { - } & \text { Market size } \\
\text { - } & \text { Market growth } \\
\text { - } & \text { Market preferences } \\
\text { - } & \text { Innovation }\end{array}$ & $\begin{array}{l}\text { - Chance: } \\
\circ \quad \text { Climate } \\
\circ \text { Political stability } \\
\text { - Competition }\end{array}$ \\
\hline
\end{tabular}

Table 7: Result of reallocation of elements of the models as input for the conceptual framework 


\section{Appendix B Important characteristics of processing tomato varieties}

In most cases, both agronomic and processing characteristics of tomatoes for industrial processing are considered in tomato processing industry. Some of the important processing characteristics for tomatoes include the following:

1. High solids content

Juices should have soluble solid level of $5^{\circ}$ Brix. This ensures that the tomatoes have sufficient solids content for tomato paste production.

2. Good bright red colour

Colour is one of the physical parameters that determine the prices of finished tomato pastes. Therefore, fully mature, red ripe tomatoes are preferred over other maturity/colour combinations in tomato processing.

3. Firm texture

Whichever processing scale (small-, medium-, or large-), the tomatoes should survive post-harvest handling, sorting and grading. Crushed, bruised tomatoes are usually discarded as they contribute to lower viscosity of the products. Aside from colour, the viscosity of reconstituted tomato pastes is another factor that influence their commercial value.

4. Fruit size

This is especially important for canned whole peeled tomatoes. The tomato should fit in the can and should not change colour and maintain the desired firmness during the canning (retort) process. 


\section{Appendix C Unit operations in tomato processing plants}

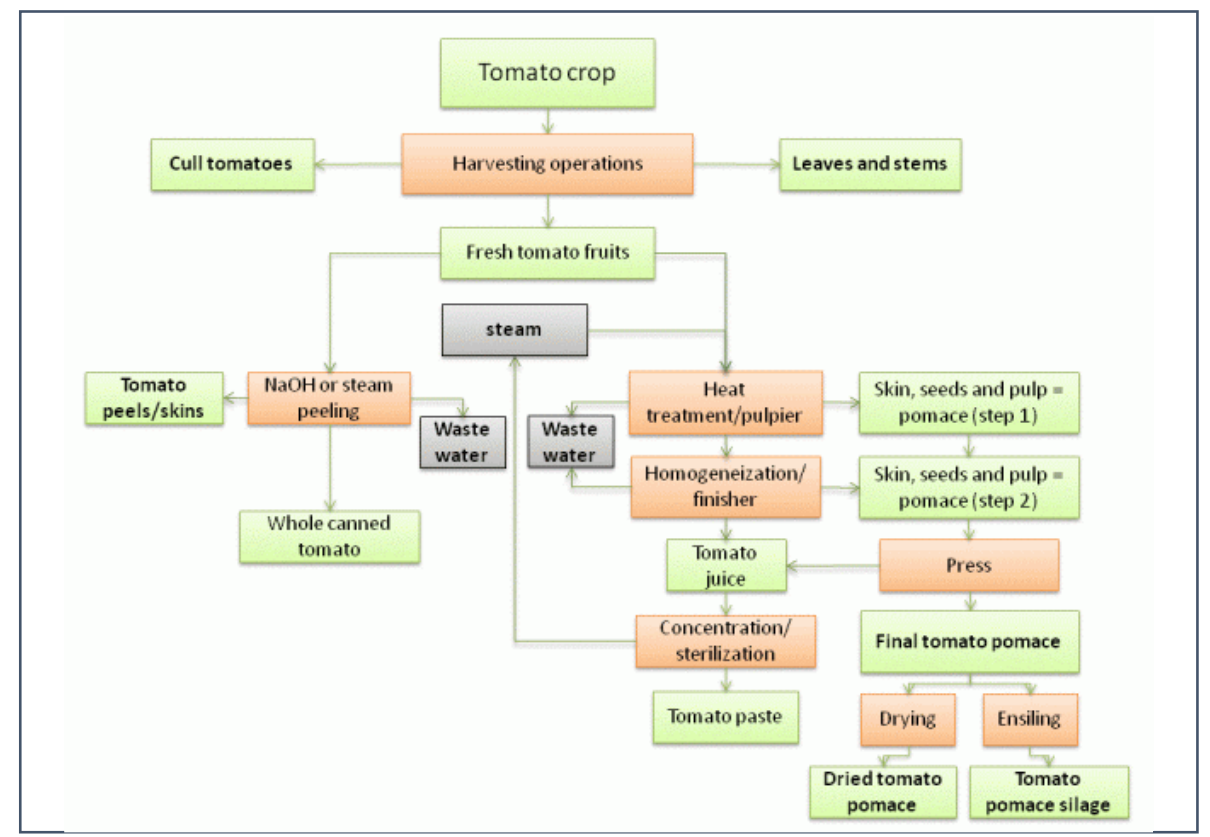

Figure 13: Schematic diagram for processing value added products from fresh tomatoes such as whole canned tomatoes and tomato paste. Side streams leading to tomato paste and silage are also shown.

1. Washing and sorting: Tomatoes are washed to remove filth, stems and other debris. Sorting of tomatoes are focused removing bruised, rotten tomatoes. Unripe tomatoes and off-colour tomatoes are also sorted in tomato processing lines. For canning operations, tomato sizes are important to consider.

2. Peeling: Peeling whole tomatoes for canning is an important unit operation for whole peeled tomato products. Peel-ability of tomatoes are determined using commercial peeling machines/equipment. Some processes use steam peeling while others use lye peeling. The specific process depends on legislation and on process preference by specific companies. Both peeling systems have their own pros and cons.

3. Tomato breaking: For tomato paste production, tomato breaking is an important step the influences that overall quality of the tomato products. There are two regimes for tomato breaking. These are hot break and cold break tomatoes. Both process specifically target pectolytic enzyme inactivation.

Hot break tomatoes are used in the production of tomato paste products. In this process, washed, sorted whole tomatoes are crushed at high temperature (about $80-85^{\circ} \mathrm{C}$ ), so that all 
pectolytic enzymes are inactivated upon crushing. This preserves the viscosity of the resulting juices that will then be evaporated to obtain high quality tomato pastes.

On the other hand, cold break tomatoes are used for the production of tomato juices. In cold breaking, washed, sorted whole tomatoes are crushed at a temperature between $65-70{ }^{\circ} \mathrm{C}$. This procedure does not inactivate all the pectolytic enzymes. As a result, the viscosity to the resulting juice is lower and the more juice yield can be obtained from the crushed tomatoes. This procedure also preserves taste and flavour of the resulting tomato juices.

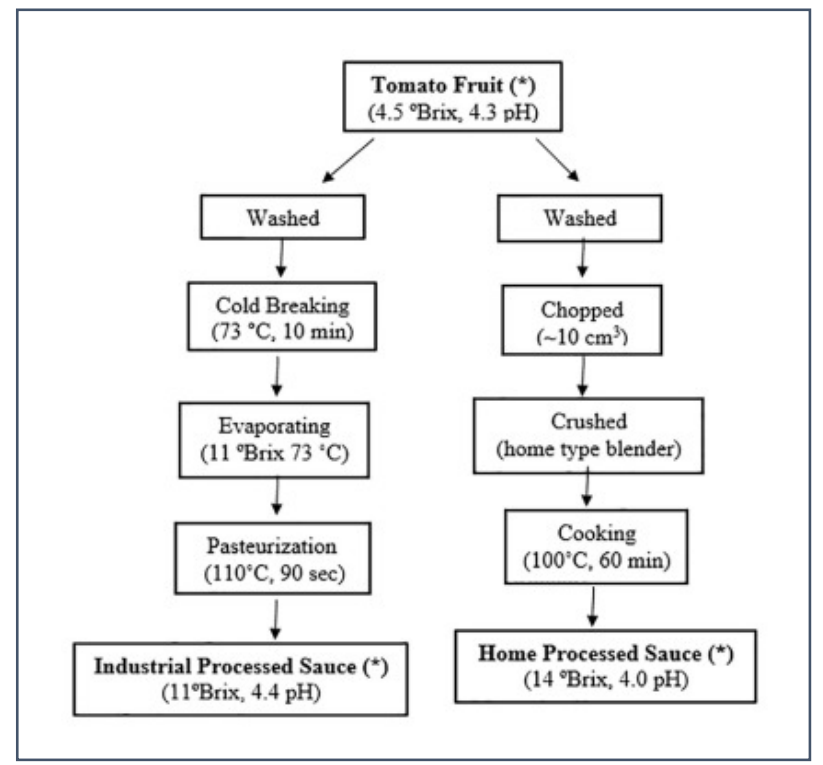

Figure 14: Process diagram showing the difference between industrial and home processed tomato sauce/juice. Hot break process is used for industrial tomato paste production

4. Size reduction/blending/homogenizing: After the tomato are crushed through a hot break of a cold break process, further size reduction is achieved in many ways depending on the scale of production. In large scale processing, break tanks are equipped with paddles that helps to break down the crushed tomatoes further. In small- and medium scale processing, blending and homogenizing may be resorted to depending on the type of tomato paste to be produced. In all cases, the main aim is the sufficiently reduce the sizes of the crushed tomatoes and not necessarily to liquefy them. Mainly because peels and seeds are usually removed from the resulting pastes. Tomato pastes with peels and seeds are usually of a lower grade quality.

5. Pulping and finishing: In large and medium scale tomato paste production, pulping and finishing follows tomato breaking. This unit operations are able to separate seeds and peels from the pulp. The peels and seeds may be used for other purposes. The equipment used for this operation is called a pulper finisher. Pulper finishers work either through centrifugal filtration or via a screw type filtration system, depending on the production scale. 
6. Evaporation: For the production of tomato pastes, usually triple effect vacuum evaporators are used. In this process, the juice (about $5^{\circ} \mathrm{Brix}$ ) is concentrated in 3 stages up to a final soluble solids content of $30-60^{\circ}$ Brix depending on the specification of the production. Vacuum evaporators are used so that the colour, flavour, and texture of the resulting tomato paste product is of high quality.

7. Packaging: Depending on the specification, finished processed tomato paste are either canned/bottled aseptically to be sold in retail consumer markets. However, industrial packages are also used for large scale costumers. In some cases, tomato pastes are stored in bulk and later processed further into other value added products.

8. Storage: Processed tomato products are stored in processing plants either for repacking, value addition depending on production schedule. 


\section{Appendix D Validation mission (May 14-19, 2018)}

\begin{tabular}{|l|l|l|}
\hline date & place & visit/meeting/interview \\
\hline May 15 & Accra & Visit Makola market \\
\hline Accra & $\begin{array}{l}\text { Meeting with Mr. Papa Bartels (Director Logistics and Value Chain, } \\
\text { Ministry of Trade and Industry) }\end{array}$ \\
\hline May 17 & Wenchi & $\begin{array}{l}\text { Interview with Mr. Kwabena Adu-Gyamfi (Managing Director of the } \\
\text { tomato processing factory at Wenchi) }\end{array}$ \\
\hline May 18 & Aechiman & $\begin{array}{l}\text { Visit tomato processing factory at Wenchi } \\
\text { Processing Complex (TEPCO) in Techiman) and visit of TEPCO }\end{array}$ \\
\hline & Kasoa & $\begin{array}{l}\text { Interview with Mr. Davies Narh Korboe (Chairman for the National } \\
\text { Farmers and Fishermen Award Winners Association of Ghana } \\
\text { (NFFAWAG), and national best mango farmer in 2008 and 2009) }\end{array}$ \\
\hline Accra & $\begin{array}{l}\text { Interview with Mrs. Love Carr (Contact person for Kokoby Food } \\
\text { Processing Company Limited) }\end{array}$ \\
\hline Women
\end{tabular}

Table 8: Travel schedule 




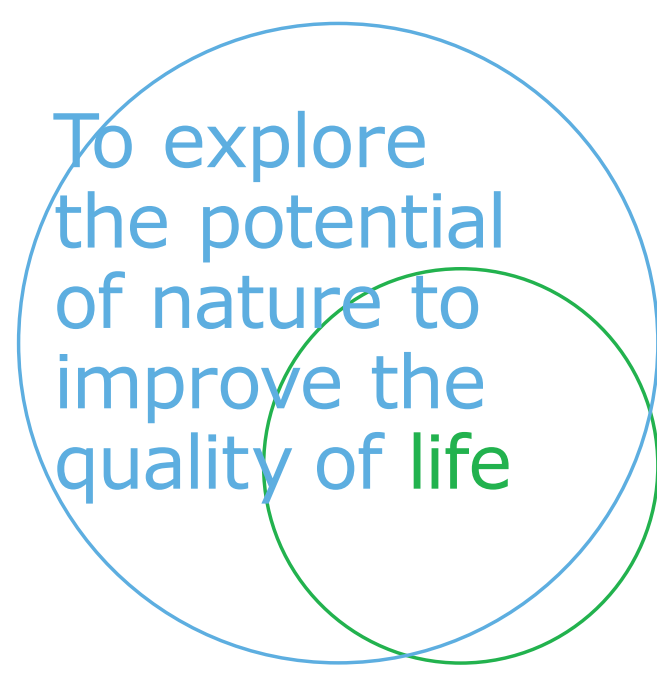

Wageningen Food \& Biobased Research Bornse Weilanden 9

6708 WG Wageningen

The Netherlands

www.wur.eu/wfbr

Einfo.wfbr@wur.nl

Report 1835

ISBN 978-94-6343-432-4

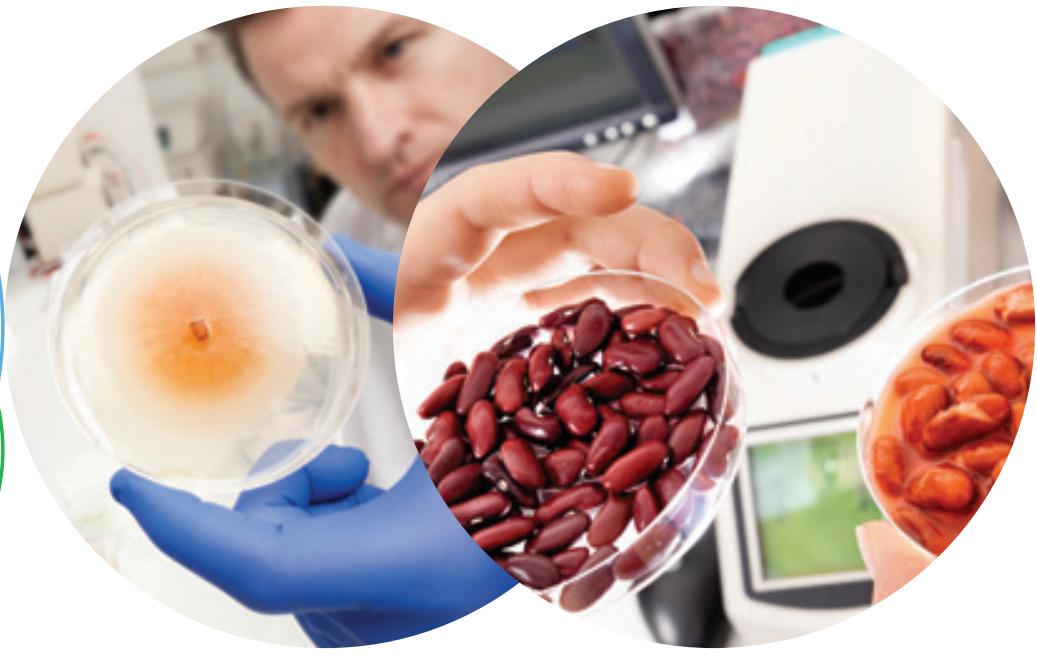

The mission of Wageningen University and Research is "To explore the potential of nature to improve the quality of life". Under the banner Wageningen University \& Research, Wageningen University and the specialised research institutes of the Wageningen Research Foundation have joined forces in contributing to finding solutions to important questions in the domain of healthy food and living environment. With its roughly 30 branches, 5,000 employees and 10,000 students, Wageningen University \& Research is one of the leading organisations in its domain. The unique Wageningen approach lies in its integrated approach to issues and the collaboration between different disciplines. 